\title{
El cosmopolitismo como teoría defensora del gobierno mundial
}

\author{
Naiara Arriola Echaniz \\ Investigadora adscrita al Departamento de Derecho Constitucional \\ Universidad de Deusto
}

Recibido: 01.10 .08

Aceptado: 15.10 .08

\begin{abstract}
Resumen: En el presente artículo se analiza la aportación de la Teoría Cosmopolita como propuesta de institucionalización supranacional superadora de las instituciones nacionales estatales. En primer lugar, se exponen las bases sobre las que se fundamenta la construcción cosmopolita -sobre todo, supuesta crisis de la institución del Estado nacional-, así como la historia y los principios generales sobre los que se basa dicha corriente. En segundo lugar, se analizan las propuestas concretas de los autores constitutivos del cosmopolitismo. En este sentido se distinguirán dos corrientes dentro del pensamiento cosmopolita: «desde arriba»y «desde abajo». En tercer lugar, se recoge el análisis crítico que realiza parte de la doctrina científica en torno, no sólo a la construcción cosmopolita propiamente dicha, sino también sobre la supuesta crisis del Estado nacional. En último lugar, se desarrolla un apartado de conclusiones.

Palabras clave: Teoría Cosmopolita, Estado nacional, Globalización, Cosmopolitismo «desde arriba», Estado cosmopolita, Cosmopolitismo «desde abajo», Democracia normativa, Estado como novísimo movimiento social.

Abstract: This article analyses cosmopolitanism as a theory which proposes a new supranational institutionalization in order to go beyond the National States. The first and the second sections summarise the fundamental framework of this theoretical construction-above all, the supposed crisis of the National State-, the history and the general principles of this scholarship. The third section studies the different schools within the cosmopolitanism: «from above» and «from below». The fourth section summarises the doctrinal criticism regarding not only the cosmopolitism proposal but also the framework which cosmopolitanism makes its proposal within. The fifth section refers to the conclusions of the article.

Key words: Cosmopolitanism, National State, Globalization, Cosmopolitanism «from above», Cosmopolitan State, Cosmopolitanism «from below», Normative Democracy, State as a new social movement.
\end{abstract}

Sumario: I. Introducción. 1. Punto de partida de la Teoría Cosmopolita. 2. Objetivos y método del presente artículo.- II. Teoría Cosmopolita. 1. Historia del pensamiento cosmopolita. 2. Corrientes ideológicas dentro del cosmopolitismo. 3. Los principios cosmopolitas.-III. Propuestas de la Teoría cosmopolita. 1. Cosmopolitismo «desde arriba». 1.1. La constitución del Estado cosmopolita. 1.2. Elementos constitutivos del Estado cosmopolita. 1.2.1. Territorio: espacio transnacional. 1.2.2. Pue- 
blo: sociedad civil cosmopolita. 1.2.3. Poder nacional: renovación conceptual. 1.3. Regulación jurídica del Estado cosmopolita: democracia cosmopolita y derecho democrático cosmopolita. 1.4. El Estado red. 1.5. Propuestas para desarrollos institucionales concretos. 2. Propuestas de la corriente cosmopolita «desde abajo». 2.1. La globalización «desde abajo»y la democracia normativa. 2.2. Globalización contrahegemónica y legalidad cosmopolita subalterna. 2.2.1. Nuevo desarrollo conceptual: sociología de las ausencias y sociología de las emergencias. 2.2.2. Vías alternativas al Estado nacional para superar las desigualdades globales. A) Políticas de igualdad y políticas de identidad. B) Reinvención del Estado nacional. C) La globalización «desde abajo». 2.3. Estado como novísimo movimiento social.-IV. Crítica a la Teoría cosmopolita.-V. Conclusiones. Bibliografía general del artículo. Bibliografía propuesta en la conclusión del artículo.

\section{INTRODUCCIÓN}

\section{Punto de partida de la Teoría Cosmopolita}

El método de desarrollo de las teorías en las disciplinas de las ciencias sociales se basa en un determinado prisma conceptual desde el cual se analiza la realidad. La Teoría Cosmopolita, que será objeto de análisis en el presente artículo, toma como punto de partida la supuesta crisis del Estado nacional y, por ende, la necesidad de redefinición conceptual de sus bases. Conceptos tales como: Edad Moderna, Estado de bienestar, soberanía nacional y autonomía estatal, poder estatal, democracia, política interior y política exterior, hegemonía del Estado nacional en el plano internacional, entre otros, han quedado desfasados por el proceso de globalización y la interconexión ${ }^{1}$ a escala mundial según, entre otros autores, aquellos que componen la corriente de pensamiento cosmopolita.

Debido a la multiplicidad de ámbitos/materias globalizados y al surgimiento de nuevos entes -empresas transnacionales, organizaciones no gubernamentales, organizaciones internacionales, organizaciones regionales- el Estado nacional ha visto disminuida su efectividad en la gestión de las competencias que le son propias e, incluso, en determinados ámbitos/materias, ha perdido la capacidad de actuación ${ }^{2}$. Esta circunstancia se ha agravado,

\footnotetext{
${ }^{1}$ En el mismo sentido que se emplea en el presente artículo el concepto «interconexión», Manuel Castells lo denomina multiculturalismo. Para una breve introducción al multilateralismo al que tiene que hacer frente el Estado nacional en la era actual, véase Castells, 2003: Vol. II, 356 a 361.

${ }^{2}$ Esta nueva situación del Estado nacional es reconocida y analizada no sólo por la doctrina cosmpolita -Beck, 2002a: 45; Castells, 2003: Vol. II, 364. Held, 1997: 169; Santos, 2005: 203, 247 y 248, entre otras, ya que es una idea que el autor mantiene presente a lo largo de toda la obra- sino también por autores ajenos a ella -Appadurai, 2001: 34 a 38; Guéhemo, 2000: 137; Rodríguez Carrión en Oliet Palá, 2003: 276-.
} 
sobre todo, por la globalización neoliberal imperante y el desarrollo de los medios de comunicación. Ante esta situación, el Estado nacional no parece capaz de mantener las facultades regulatorias en todas las competencias que le otorga el ordenamiento jurídico nacional y podría estar siendo superado por las circunstancias y situado, incluso, en un último extremo, ante su final; esto es, el periodo actual plantea la posibilidad de superación del Estado nacional como institución de integración social y política imperante ${ }^{3}$.

La situación actual, brevemente expuesta, podría definirse por dos notas características: transición, por un lado, y complejidad, por otro. La «transicionalidad» del periodo actual se justifica porque el proceso globalizador contemporáneo está minando las bases sobre las que se sustenta el modelo contemporáneo de organización social y política, es decir, el Estado nacional y su orden establecido ${ }^{4}$.

La complejidad de la realidad en la que estamos inmersos se debe a la interconexión, esto es, como consecuencia de la globalización actual se han interconectado a nivel mundial la economía, la política, la cultura, la sociedad e, incluso, los problemas. La consecuencia de esto es la necesidad de que en el desarrollo de la actividad política nacional se tengan en cuenta no sólo factores nacionales. El exponente negativo paradigmático de esta nueva situación son los llamados problemas globales. Así, los problemas que antes eran producidos y solucionados a nivel nacional se han globalizado. Esto tiene como consecuencia la necesidad de un avance y redefinición de los conceptos clásicos de la ciencia política para dar soluciones eficaces a los problemas globales del siglo $\mathrm{XXI}^{5}$. Los problemas globales son aquellos que producen sus efectos negativos en varios Estados o, incluso, a lo largo de todo

${ }^{3}$ Las mayores disfuncionalidades del Estado nacional surgen con respecto a lo siguiente: 1) Poder económico nacional; 2) Prestación de servicios públicos; 3) Recaudación fiscal; 4) Seguridad nacional; 5) Poder jurisdicción nacional; 6) Gestión de las desigualdades sociales; 7) Control del territorio nacional.

${ }^{4} \mathrm{La}$ creencia de que nos encontramos en un periodo de cambio paradigmático es compartida por varios autores, no todos ellos cosmopolitas. Por ejemplo, véanse Faria, 2001: 38 a 42; Santos, 2005: 297; Touraine, 2005: 16.

${ }_{5}$ Para el reconocimiento de los problemas políticos como problemas globales, Fulvio Attinà defiende la necesidad de crear una agenda global. Este autor afirma que para que cualquier tema pueda tratarse en la vida política es necesario que sea incluido en la política global por alguno de los sujetos políticos activos en dicha instancia (2001: «Capítulo 4: Globalización y nueva agenda», 157 a 252). El término «agenda global» puede parecer un tanto impreciso. Este concepto se utiliza para aglutinar de forma genérica todos aquellos problemas que han surgido derivados de la globalización y que no se puede resolver de forma autónoma por los distintos Estados nacionales sino que necesitan de la cooperación transnacional. Las consecuencias negativas de la globalización se pueden entender incluidas en la agenda global cuando su problemática se haya visto como un objeto que necesita de la acción política para su gestión y/o solución. David Held, acuña el concepto de problemas «intermésticos» para referirse al incremento de problemas para cuya gestión y solución se necesitan la combinación de política nacional y política internacional (2005: 132). 
el globo. Este concepto se refiere, por ejemplo, al problema del calentamiento global, la crisis medioambiental global, las epidemias globales, el crimen global, la inestabilidad financiera global o el terrorismo global (Castells, 2003: Vol. II, 357).

Esta situación exige una reflexión profunda sobre los aspectos fundamentales de nuestras organizaciones sociales y políticas para aportar alternativas institucionales superadoras de ésta. La Teoría Cosmopolita se presenta a sí misma, grosso modo, como una propuesta de este tipo, es decir, como una propuesta de organización social y política alternativa a la figura del Estado nacional, que aboga por la institucionalización de la democracia a nivel mundial, consensuada entre actores estatales y no estatales, centrada, sobre todo, en garantizar el respeto los derechos sociales y políticos de todos los ciudadanos del mundo.

\section{Objetivos y método del presente artículo}

En el presente artículo se intentará presentar y analizar críticamente la construcción cosmopolita como una posible alternativa superadora de la institución del Estado nacional. Este enfoque ha tenido como consecuencia que se preste menor atención a otros aspectos que también han sido estudiados por los autores cosmopolitas, tales como la cuestión de la guerra justa, la implantación a nivel mundial de los derechos humanos o la regulación transnacional sobre medio ambiente. Esta circunstancia se debe únicamente a la necesidad de concreción propia de un artículo de investigación.

Es necesario establecer aquí otra salvedad, se podría decir. En el texto que nos ocupa, se han intentado exponer las distintas propuestas de los autores cosmopolitas desarrollándolas en conjunto, como si de una construcción teórica común se tratase. Con esto, se ha intentado dotar de mayor coherencia a toda la Teoría y aportar un punto de vista común a la crisis del Estado nacional entre todos los autores cosmopolitas aunque, en todo momento, se han intentado señalar las diferencias o los matices encontrados entre los autores analizados.

En el desarrollo del presente artículo, se han manejado también obras de autores «no cosmopolitas». Esto se debe a que dichos autores, aun no defendiendo la propuesta alternativa de la Teoría Cosmopolita, sí coinciden en todas o algunas de las concepciones cosmopolitas sobre los supuestos aspectos en crisis del Estado nacional, así como en la posible necesidad de una reforma en todos o en parte de los conceptos de la ciencia política clásica.

Como esquema general de este artículo se podrían enumerar los siguientes apartados. En primer lugar, se va a desarrollar un breve análisis de esta escuela de pensamiento distinguiendo entre las dos corrientes que la forman, así como aquellos autores próximos a ellas. En segundo lugar, se desarrollará un análisis crítico de ésta y se recogerán algunas aportaciones alternativas que, desde otros sectores de la doctrina científica, se le hacen. Por último, a 
modo de conclusión, se presentará el estado actual del debate doctrinal en torno a esta cuestión, así como una exposición breve de las vías de investigación abiertas encontradas alrededor de algunas de las cuestiones analizadas en el presente artículo, sobre todo, el análisis de la situación real del Estado nacional y la necesidad y/o validez de las propuestas alternativas a éste.

\section{TEORÍA COSMOPOLITA}

El cosmopolitismo debe ser entendido «como el reconocimiento del otro, incluido el otro cultural, como un proyecto democrático que lucha por una ampliación de la democracia en el espacio transnacional, es decir, por una democracia experimental (...), finalmente, como una ordenanza-marco para la economía desterritorializada, un marco que posibilite que sea la política la que vuelva a marcar las pautas de la humanidad, es decir, un trabajar $\mathrm{y}$ un vivir humanamente dignos, y un trato a la naturaleza igualmente respetuoso y digno» (Beck, 2002a: 55).

El objetivo final de la propuesta cosmopolita es la repolitización de las nuevas estructuras de poder que, en la actualidad, superan al Estado nacional en algunos de sus ámbitos competenciales. El ordenamiento jurídico nacional debe rebasar el nivel nacional en la regulación de aquellos ámbitos en los que éste sea disfuncional en su control o en su gestión, y apoyarse en nuevas fuentes de legitimidad, bien en organizaciones locales, regionales, internacionales o supranacionales. Así, esta Teoría debe entenderse como una forma o una posible vía para enfrentarse y superar, tanto la anomia de la globalización económica imperante, como los efectos negativos que ésta conlleva, no sólo para las instituciones políticas, nacionales y/o internacionales, sino también para los individuos, el medio ambiente, la sanidad y la cultura, entre otros.

Como ya se ha apuntado en el presente artículo, se tratará el análisis de la Teoría Cosmopolita únicamente en relación con las instituciones políticas, sobre todo, con el Estado nacional. Con lo apuntado hasta ahora, se puede intuir, según la opinión de esta Teoría, que los elementos clásicos constitutivos del Estado nacional (poder, pueblo y territorio) deberán mutar o reformularse para formar parte del Estado cosmopolita (poder transnacional, sociedad global y espacio transnacional).

La Teoría Cosmopolita parte de la base de una superación conceptual metodológica, esto es, dicha corriente doctrinal comparte la opinión de que términos metodológicos entendidos como clásicos, en el sentido de las ciencias sociales, han quedado obsoletos. Principalmente, se refieren a los siguientes:

a) Nacionalismo metodológico: el Estado nación es el marco de referencia empleado para los análisis que desarrollan las distintas ciencias sociales. Por utilizar una expresión muy gráfica de Richard Falk, esta 
corriente metodológica sigue anclada en un mundo de «sombras westfalianas» $(2002,201)^{6}$.

b) Realismo político: es una corriente de pensamiento que, por definición, es contraria a la propuesta cosmopolita, ya que aquélla entiende que los Estados nacionales siguen conservando su papel hegemónico en el plano internacional y que el proceso de globalización no ha minado ni la soberanía, ni el poder, ni, por tanto, las competencias que les son reconocidas en sus distintas constituciones.

c) Teoría del contenedor social: es un concepto sociológico que se refiere a la necesidad de las distintas sociedades nacionales de desarrollar sus actuaciones y demandas en un marco geográficamente delimitado, como es el del Estado nacional al que pertenecen. Las fronteras nacionales, según esta teoría, agrupan a las sociedades y establecen el ámbito en el que hacer valer sus propuestas.

d) Neoliberalismo: doctrina tanto económica como política que aboga por una mínima intervención del poder político en el plano económico. En la actualidad, es la corriente definitoria de la globalización económica y defiende, en este campo en concreto, la libertad de movimiento de los capitales y de los flujos financieros a nivel mundial sin necesidad de ninguna regulación externa a la que se establezca por el libre juego del mercado mundial.

e) Primera Modernidad o Edad Moderna: Los Estados nacionales son el prisma desde el cual se desarrollan las investigaciones de las ciencias sociales. Sin embargo, sobre todo para los autores cosmopolitas, en del desarrollo de sus investigaciones sociológicas, la hegemonía metodológica de esta institución se ha visto superada por el desarrollo de la economía mundial, el avance tecnológico y por el proceso de globalización. Por lo tanto, en la actualidad es necesario el desarrollo de una nueva metodología que supere el axioma nacional. De este cambio de paradigma explicativo se deriva que los autores contrarios, sobre todo, a la globalización hegemónica actual distingan entre primera y segunda modernidad, entendiendo por primera modernidad aquella en que los Estados nacionales mantenían su posición hegemónica como institución política organizadora de la vida social. La segunda modernidad, por el contrario, nos introduce en una era postnacional donde estos actores estatales han perdido su hegemonía. Debido a esto, ya no es posible utilizar ni la vieja metodología ni el

\footnotetext{
${ }^{6}$ Para ampliar la reflexión de la Teoría Cosmopolita sobre el nacionalismo metodológico véase Beck, 2005: «Crítica de la mirada nacional y del nacionalismo metodológico», 38 a 51. En este apartado, Ulrich Beck desgrana su posición frente a una metodología ya superada por la realidad, analizando sus principales características y sus malentendidos en relación con conceptos como sociedad universal, pluralidad cultural, relación entre nacional e internacional, entre otros.
} 
viejo marco teórico de análisis ${ }^{7}$. En la actualidad, los Estados nacionales están excesivamente limitados por factores geográficos. Este hecho les impide enfrentarse con eficacia a las amenazas y los riesgos globales. Esta incapacidad se debe, entre otros factores, a que fueron pensadas como instituciones de gobierno excluyente, no incluyentes (Rifkin, 2004: 344). Es necesario, por tanto, un cambio en el marco conceptual explicativo de las ciencias sociales para adecuarse al nuevo contexto postnacional. Sin embargo, Alain Touraine se muestra cauto con la postmodernidad, ya que ésta tiene como consecuencia la desaparición de todo principio histórico central que defina el conjunto social. Esto aporta a la postura intelectual que la adopte posibilidades infinitas de conceptualización y, al mismo tiempo, les expone a graves peligros de desorganización teórica y práctica (2005: 95).

\section{Historia del pensamiento cosmopolita}

La aparición del término «cosmopolitismo» se sitúa en la escuela griega de los estoicos y llega hasta nuestros días. El análisis del proceso de evolución histórica del concepto «cosmopolitismo» y de las escuelas de pensamiento unidas a él es excesivamente extenso para el presente artículo. Por esta razón, se situará el precedente histórico a la actual Teoría Cosmopolita en la obra de Immanuel Kant. Más concretamente, en su ensayo, Sobre la paz perpetua $^{8}$, donde el citado autor construye su argumento a favor de la creación de una federación de Estados nacionales democráticos, representativos de la comunidad internacional, constituida de forma voluntaria por dichos Estados para asegurar, sobre todo, una paz estable y duradera a nivel mundial.

La instauración de dicha federación pacífica entre los Estados nacionales democráticos cumple dos objetivos fundamentales: el primero lo constituye la necesidad de superar el estado de naturaleza de las relaciones interestatales a nivel internacional; el segundo es poner fin a todas las guerras, y no sólo a una guerra concreta, es decir, avanzar más allá del objetivo limitado a

\footnotetext{
${ }^{7}$ Para ver más información sobre esta cuestión véase Beck, 2002a: 7 a 64. Sobre un análisis de la modernidad y la posmodernidad, en el campo eminentemente sociológico, véase Bauman, 2001b. El autor desarrolla una reflexión en determinados ámbitos como la cultura, la concepción del individuo, la moral, la religión, para analizar, sobre todo, los aspectos negativos de la nueva era y determinar que los conceptos tradicionales de metodología sociológica deben adecuarse al nuevo panorama mundial de comienzos del siglo XXI. Sobre la necesidad de un cambio conceptual en la sociología también está a favor Nederveen Pieterse en Featherstone, Lash y Robertson, 1995: 63. Para un análisis político sobre esta misma cuestión, véase Bauman, 2001a. Otros autores, ajenos al movimiento cosmopolita, también reconocen que, en la actualidad, caminamos hacia un mundo postnacional; véanse, por ejemplo, Appadurai, 1996: 167; Boys, 2004: 52; Monedero en Santos, 2005: 19 a 37; Rifkin, 2000: 249 a 260.

${ }^{8}$ Obra escrita por el citado autor en 1795, su título original es Zum ewigen Frieden. En el presente artículo se ha manejado una traducción de F. Riera Pastor, de 1979.
} 
una guerra concreta tal y como hacen los distintos tratados de paz alcanzados a lo largo de la historia.

Para alcanzar estos objetivos es necesario que, al menos, una República ${ }^{9}$ decida ser el centro de esta República universal. En el supuesto de que los Estados nacionales no sean capaces de llegar a constituir dicha República universal, se propone la constitución de una Federación de pueblos.

Esta Federación no se orienta hacia la creación de una ciudadanía mundial, pero sí sería conveniente que se dotase de una constitución cosmopolita y se elaborase un derecho de ciudadanía mundial. La mencionada constitución cosmopolita debe entenderse en el sentido de una regulación jurídica de las relaciones públicas, caracterizadas por el pacifismo, mantenidas entre los distintos pueblos que formen parte de la Federación.

En relación con la elaboración de un derecho de ciudadanía mundial, el incremento de la interconexión a nivel mundial exigirá su desarrollo. Según Immanuel Kant, este derecho de ciudadanía mundial «(...) no es una fantasía jurídica, sino un complemento necesario del código no escrito del derecho político y de gentes, que de ese modo [es decir, por el aumento de la interconexión interestatal a nivel mundial $]^{10}$ se eleva a la categoría de derecho público de la Humanidad y favorece la paz perpetua, siendo la condición necesaria para que pueda abrigarse la esperanza de una continua aproximación al Estado pacífico» (1979: 117).

El objetivo de la paz perpetua a nivel mundial, en la actualidad, se ha visto complementado por otro tipo de necesidades cubiertas por los distintos Estados nacionales -véase por ejemplo, el desarrollo y la implantación del Estado de Bienestar-. Como consecuencia de lo anterior, a nivel mundial ya no sólo debe perseguirse el establecimiento definitivo de la paz mundial, sino que también es necesario que se alcance un desarrollo, económico, social, cultural y político para toda la humanidad.

Otro autor que es importante destacar, en este breve repaso histórico de la Teoría Cosmopolita, es Hans Kelsen. Autor influido por Immanuel Kant en el desarrollo de su concepción sobre el Derecho internacional y también en su propuesta cosmopolita, considera que el Derecho internacional debe entenderse como coactivo y superior a los ordenamientos jurídicos nacionales y que sólo la garantía de esta jerarquía normativa puede mantener la paz entre la comunidad internacional, compuesta por Estados nacionales soberanos $(2003)^{11}$. El citado autor es cauto con la creación de una comunidad jurí-

${ }^{9}$ El concepto de República, en este contexto, debe ser entendido como una forma de gobierno en la que prima la separación de poderes. En este término en concreto, la separación debe darse, sobre todo, entre el poder legislativo y el poder ejecutivo. La República también se caracteriza por desarrollarse bajo la forma de una democracia representativa (Kant, 1979: 104 y 105).

${ }^{10}$ El corchete no aparece en el texto citado pero clarifica la comprensión de la nota.

${ }^{11}$ La publicación original de La paz por medio del derecho es de 1944, en California. El título de la publicación en inglés es Peace through Law. Traducción de Luis Echávarri. 
dica, constituida sobre la base del Derecho internacional, con el nombre de Civitas máxima, o de Estado mundial. Esta nueva creación institucional será sólo posible sobre el supuesto de que tomemos la palabra Estado en un sentido lato. «Ahora bien, queda claramente sentado que desde el punto de vista jurídico, nada obsta para que se puede realizar ulteriormente una tal evolución técnica; no lo impide ni la esencia del Estado, ni la de su soberanía, ni la del Derecho internacional, ni la del Derecho pura y simplemente. Cosa distinta es, en cambio, la opinión que se pronuncie sobre este tema desde el punto de vista de la ideología política; a tenor de los diversos idearios, unos reputarán tal evolución como posible, otros como imposible; unos la estimarán saludable, otros, funesta.» (1934: 148) $)^{12}$.

El citado autor reincide en la posibilidad de una organización jurídica mundial. El mayor problema que se encuentra, en el desarrollo práctico de esta cuestión, es la soberanía nacional de los distintos Estados, pero la decisión última la tienen ellos mismos y, por tanto, no se trata de una respuesta jurídica, sino de una cuestión política (2001: 98 y 100) ${ }^{13}$.

Para el efectivo mantenimiento de la paz a nivel mundial, Hans Kelsen aboga por la creación de un Tribunal internacional aceptado y reconocido por todos los Estados nacionales, encargado de controlar la legalidad de todas las actuaciones estatales (2003).

Los procesos de globalización actuales nos han conectado de tal modo, que los distintos Estados nacionales no pueden cerrarse a ellos y deben combatir conjuntamente y cooperando sus efectos negativos, que perjudican más a unas zonas del mundo que a otras. Este objetivo genérico es seguido por la Teoría Cosmopolita que se expondrá a continuación ${ }^{14}$.

\section{Corrientes ideológicas dentro del cosmopolitismo}

El cosmopolitismo es una teoría moral y política que, basada especialmente en su compromiso con una serie de patrones universales, derechos humanos y valores democráticos, intenta establecer los principios generales y las nuevas instituciones políticas, por medio de las cuales se pueda hacer

\footnotetext{
${ }^{12}$ La obra original de la Teoría General del Derecho fue publicada en 1925. La publicación manejada en el presente artículo es un compendio traducido por Luis Rechaséns Fiches y Justino de Azcárate.

${ }^{13}$ Para una breve introducción a la relación entre Derecho nacional y Derecho internacional según Hans Kelsen véase Kelsen, 2001: «11. La Relación entre Derecho nacional e internacional», 81 a 100 y «12. Doctrina jurídica y concepción del mundo», 101 a 105 . La obra original de Teoría Pura del Derecho se escribió en 1935, pero en el presente artículo se ha manejado una traducción de 2001. Se debe aclarar también que la obra analizada para este artículo es una Introducción a dicha Teoría Pura del Derecho, desarrollada por Emilio O. Rabasa.

${ }^{14}$ Para ampliar el estudio sobre el origen y la historia del cosmopolitismo véanse Beck, 2002a: 184 a 187; Beck, 2004: 70; Nussbaum, 1999: 17 a 22 y Zolo, 2000: 141 a 147.
} 
frente a la supuesta situación de disfuncionalidad o, incluso, decadencia de los distintos Estados nacionales contemporáneos a nivel mundial. Este nuevo cosmopolitismo contemporáneo debe mostrarse multicultural, articulador de diferencias y reconocedor de las identidades no diferenciadoras horizontalmente (Santos, 2005: 233).

La corriente cosmopolita no es una escuela de pensamiento homogénea sino que, dentro de ella, en su desarrollo actual, los autores que la componen tienen, según la opinión defendida en el presente artículo, algunas diferencias. Éstas se evidencian, sobre todo, en el momento en que los autores de estas corrientes exponen sus propuestas alternativas y superadoras de la crisis del Estado nacional, concretamente, atendiendo a la institución o al elemento político, social o cultural, desde el cual se podría o se debería institucionalizar el ideal cosmopolita, en la actualidad. En este sentido, en el presente artículo, distinguiremos entre cosmopolitismo «desde arriba» y cosmopolitismo «desde abajo» ${ }^{15}$. La primera corriente aboga porque los principios cosmopolitas se desarrollen jurídicamente como rectores de la sociedad. Este escenario jurídico novedoso se conseguirá a través de un proceso institucional, promovido por los Estados nacionales democráticos. La finalidad de este desarrollo cosmopolita es controlar y gestionar la situación mundial actual superando, para ello, la forma de organización social y política de los Estados nacionales actuales. La propuesta cosmopolita «desde arriba», por tanto, intenta establecer los principios cosmopolitas en instituciones políticas, sociales y económicas, para que consigan reformular la naturaleza y la forma de gobierno actual tanto a nivel nacional como internacional, desde el prisma de la democracia cosmopolita y del derecho democrático cosmopolita. Como máximos exponentes del cosmopolitismo «desde arriba» destacan Ulrich Beck y David Held. El primero de éstos, Ulrich Beck $^{16}$, se encarga de distanciarse de otros autores como Niklas Luhmann e Immanuel Wallerstein, ya que para él siguen sujetos al paradigma nacional cuyo cosmopolitismo quiere superar completamente.

\footnotetext{
${ }^{15}$ Desde la doctrina internacional se desarrollan otras distinciones para la Teoría Cosmopolita. Así, Danilo Zolo enmarca a Antonio Cassese, David Held y Richard Falk dentro del cosmopolitismo «legal, jurídico o kelsiano» (2000: 140, 151 y 161, respectivamente), entendiendo por tal aquella corriente de pensamiento que ve superada la soberanía nacional de los distintos Estados como consecuencia de los procesos de globalización y aboga, entre otras cosas, por el establecimiento de instituciones de carácter supranacional para hacer frente a todas aquellas situaciones en que los Estados nacionales autónomamente no pueden controlar ni gestionar, así como por la instauración y garantía de los derechos humanos a nivel mundial. En cambio, Fulvio Attinà incluye a David Held y a Richard Falk, junto con Papisca, en la Teoría de la democracia internacional (2001: 78). En este sentido, dentro del marco del Derecho internacional, la corriente cosmopolitista es entendida como una vía de estudio de la democratización no sólo del sistema de Estados nacionales, sino también de todo el sistema global surgido en esta era de la globalización.

${ }^{16}$ Para una introducción al pensamiento más reciente de Ulrich Beck véase Alfier, 2006.
} 
Las propuestas del Ulrich Beck y David Held, además, tienen un alto componente jurídico. Estos autores reconocen que para avanzar en la instauración de su propuesta cosmopolita deben hacerlo por la senda del derecho no sólo a nivel nacional, sino creando un ordenamiento jurídico superior, esto es, supranacional.

Otro autor que también ha sido incluido en el desarrollo de la propuesta cosmopolita «desde arriba» es Manuel Castells. Esta decisión se debe, sobre todo, a que su desarrollo del Estado red conecta con el Estado cosmopolita propuesto por los dos autores anteriores ${ }^{17}$.

La segunda corriente de la Teoría, es decir, la corriente cosmopolita «desde abajo», sin embargo, considera que, para que los ideales cosmopolitas tengan un desarrollo institucional óptimo, es necesario que se impulse este proceso por medio de la movilización social. En esta segunda corriente, el desarrollo de las instituciones cosmopolitas vendrá impulsado por la acción social, bien a través de asociaciones civiles, bien por medio de otros organismos que encaucen la acción política social.

El cosmopolitismo «desde abajo» cuenta con dos exponentes destacados: Richard Falk y Boaventura de Sousa Santos. Ambos autores comparten la creencia de que la institucionalización de la propuesta cosmopolita tendrá su origen en la movilización social. El primero de ambos, Richard Falk, afirma que ha sido influido por David Held en el desarrollo de su propuesta (2002: 213).

Juan Carlos Monedero (en Santos, 2005: 42) desarrolla un breve análisis comparativo entre Ulrich Beck y Boaventura de Sousa Santos que podría ser de utilidad para establecer los puntos de conexión, así como los de mayor diferenciación entre ambas corrientes. Así, Ulrich Beck ha planteado la necesidad de una «nueva teoría crítica» que supere los análisis centrados en el Estado nacional, insistiendo en su idea de que estamos en la transición hacia la posmodernidad. Los puntos de encuentro entre ambos autores son la necesidad de pensar desde el concepto de sociedad mundial; la diferenciación entre formas de operar paradigmáticas y subparadigmáticas -según Santoso categorías zombies -según Beck-; la separación analítica entre Estado, mercado y comunidad/sociedad civil; la idea de frontera; la condición autocrítica del pensamiento; la otredad de los otros. En esta línea de destacar los puntos de encuentro, es necesario concluir diciendo que su propuesta de superación cosmopolita del Estado nacional tiene rasgos de gran construcción teórica que ahoga las diferencias, que se reducen al camino de su institucionalización. Generalizando las aportaciones de Juan Carlos Monedero, se podría decir que ambas corrientes de la Teoría Cosmopolita coinciden en

${ }^{17}$ Esta idea, quizás, parece ahora un tanto incompleta pero será explicada en un momento posterior del artículo. Cuando se analicen tanto el Estado cosmopolita como, sobre todo, el Estado red. 
el análisis de la realidad, en los efectos que ésta tiene sobre las instituciones políticas actuales, así como en la necesidad de repensar éstas ${ }^{18}$.

Otros autores que habría que destacar en esta construcción teórica cosmopolita son Gerard Delanty, Anthony Giddens, Martha C. Nussbaum y Norbert Bildeny, entre otros, que también serán analizados en el presente análisis de la Teoría Cosmopolita.

\section{Los principios cosmopolitas}

Serán entendidos por tales aquellos indicios y valores que ayudarán a determinar cómo debe ser entendida la Teoría Cosmopolita en la actualidad y las características genéricas a las que deberán sujetarse las propuestas de los autores que se definan como cosmopolitas ${ }^{19}$. Para su concreción seguiremos, sobre todo, la exposición de David Held ${ }^{20}$.

a) En un primer grupo, se encuentran los principios que se refieren a los derechos fundamentales que deben ser respetados a nivel mundial y garantizados a todas las personas con independencia de su Estado nacional de residencia o de origen. Este nuevo derecho global superará al derecho internacional, ya que el primero se regirá por el prin-

${ }^{18}$ En el presente artículo, los puntos de conexión entre ambas teorías se podrán apreciar en el apartado «1.2. Elementos constitutivos del Estado cosmopolita». En este apartado no sólo se desarrollará un análisis de los nuevos elementos propuestos, sino también la justificación cosmopolita sobre la necesidad del cambio. Uno de los puntos de mayor afinidad entre ambas corrientes, similar análisis de la realidad y similar propuesta. Su mayor diferencia, como ya se ha apuntado, se encuentra en el modo en lograr la superación de la supuesta situación actual de disfuncionalidad y/o crisis del Estado nacional.

${ }^{19} \mathrm{El}$ desarrollo de estos principios está orientado a la consecución de los objetivos cosmopolitas que encajan, sobre todo con la corriente cosmopolita «desde arriba». En el caso de la corriente cosmopolita «desde abajo», estos principios podrán ser tenidos en cuenta en la medida en que no contradigan el propio flujo de cambio orientado desde la movilización social hacia las instituciones. En este segundo caso, quizás, sean más directamente aplicables los principios enunciados por Boaventura de Sousa Santos como propios del cosmopolitismo: a) no basta con elaborar alternativas, se necesita un pensamiento alternativo sobre las alternativas; b) se debe pasar del conocimiento a la acción; c) la reinvención de los espacios-tiempo que promuevan la deliberación democrática (2005: 358 a 360). El último de estos principios también es destacado por David Held -véase, por ejemplo, el principio $e$ del presente apartado-; este hecho de debe a la importancia que adquiere la participación democrática, como necesidad irrenunciable de cualquier construcción política cosmopolita.

${ }^{20}$ En Held, 2005: «Los fundamentos de un nuevo internacionalismo: Los principios cosmopolitas», 213 a 228. En el desarrollo del presente artículo se establecerá una agrupación más global de dichos principios cosmopolitas para que resulten más manejables y más fácilmente analizables. Para una introducción al tema de los principios que rigen genéricamente la Teoría cosmopolita véase también Domingo, Rafael en Caicedo, Domingo y Santiváñez (coordinadores), 2006: «Principios del derecho global», 25 a 28. 
cipio de personalidad y no por el principio de territorialidad que sirve como fundamento del derecho internacional actual.

b) En segundo lugar, todos los seres humanos deben tener reconocida una capacidad de acción activa o de autodeterminación, es decir, a todo ser humano se le debe reconocer una capacidad de elección. Lo que a su vez incluye la posibilidad y el respeto a actuar de otra manera.

c) En tercer lugar, los derechos que deben ser reconocidos a todo ser humano también generan deberes sobre ellos. Por tanto, todo individuo debe hacerse responsable de las consecuencias de sus actos.

Estos tres primeros apartados $-a, b$ y $c-$ sientan la base fundamental sobre la que se desarrolla la moral cosmopolita.

d) Para el establecimiento y desarrollo de los tres principios anteriores es necesaria la celebración de un proceso de decisión política no coactivo (principio de consentimiento). Éste se expresa por medio de una práctica de voto. Así, quedan superadas las formas más estrictas de decisión política, como puede ser el caso de la unanimidad.

El procedimiento que habría que adoptar para la libre toma de decisión exige que sean tenidos en cuenta tanto el principio de inclusión como el principio de subsidiariedad, para asegurar dicha libertad en las formas de partición. El desarrollo de estos principios está siendo ampliamente debatido en la toma de decisiones transnacionales, téngase por ejemplo en cuenta la problemática existente en torno a la Unión Europea por su falta de legitimidad democrática en la adopción de sus decisiones.

Este cuarto apartado de principios ${ }^{21}$ proporciona la base para el establecimiento, en un momento posterior, de los marcos de acción u ordenamientos reguladores que desarrollen las decisiones colectivamente aceptadas. Con este objetivo último, se trata de forma indirecta de superar el déficit democrático del que son acusadas las distintas organizaciones internacionales.

e) Ante la toma de cualquier decisión política debe evitarse la producción de cualquier tipo de daño y su reparación en caso de haberse producido. Además, toda decisión política tomada debe respetar el principio de sostenibilidad en todo el mundo.

Este último apartado 22 establece el orden de toma de decisión (según su urgencia) y la necesidad de conservar los recursos no sólo a nivel nacional sino a nivel mundial.

${ }^{21}$ A partir de este momento, nos separamos de la división hecha por el autor, entendiendo que una exposición más resumida es suficiente para la comprensión y el análisis de dichos principios. Este cuarto apartado (apartado $d$ ) del presente proyecto de investigación agrupa los principios cuarto, quinto y sexto en Held, 2005: 217 y 218.

${ }^{21}$ Este apartado quinto (apartado $e$ ) del presente proyecto de investigación agrupa a los principios séptimo y octavo en Held, 2005: 218 a 220. 
Estos principios pueden considerarse como «la base ética rectora para la socialdemocracia global» (2005: 222). Se debe superar la creencia de que tales principios son propiedad de la cultura occidental, ya que con ello se superará también la mirada nacional. Los autores cosmopolitas consideran que tales principios son de aplicación a nivel mundial y que dicha aplicación puede ayudar a un mejor desarrollo y participación de la sociedad civil a nivel mundial. Esta postura no es compartida por sociedades distintas a la occidental, tales como la musulmana, la asiática o la africana, que consideran tales principios como una nueva forma de colonización por parte de los Estados nacionales occidentales ${ }^{23}$.

\section{PROPUESTAS DE LA TEORÍA COSMOPOLITA}

La Teoría Cosmopolita propone una regulación jurídica e institucional que, avanzando más allá de la construcción política del Estado nacional, sea capaz de resolver los problemas actuales que han aparecido como consecuencia del proceso de globalización.

Este grupo de autores trata de dar respuesta a preguntas como éstas: ¿se ha superado definitivamente la figura del Estado nacional en la era global?, ¿cuál debe ser la forma social de integración social y política en la era de la globalización?, ¿son adecuados sus análisis teóricos y sus propuestas jurídico-políticas para la situación mundial actual?, ¿es posible la creación de un Estado cosmopolita?, ¿cómo debe desarrollarse la institucionalización de los principios cosmopolitas?, ¿cuáles deben de ser los nuevos significados de Estado, reparto de poder, soberanía, ciudadanía?

En definitiva, lo que se propone desde la Teoría Cosmopolita es avanzar hacia la globalización, pero hacia «otra» globalización, esto es, una globalización que tenga como resultado una legislación transnacional, superadora de los ordenamientos jurídicos propios de los Estados nacionales, y una economía política solidaria, que tenga como características inherentes principales, su carácter democrático y su preocupación por mitigar y, en última instancia, acabar con los efectos negativos del proceso globalizador imperante en la actualidad. En este sentido, esta corriente no es contraria a la globalización, en sí misma considerada, sino que se opone a la globalización neoliberal hegemónica, es decir, a una globalización exclusivamente financiera que no es capaz de avanzar más allá del máximo beneficio alcanzable, que no se detiene en reducir sus externalidades negativas sobre el medio ambiente que está destruyendo, ni sobre las desigual-

${ }^{23}$ El debate en relación con el carácter occidental o incluso la forma de nuevo imperialismo que adoptan los procesos de globalización actuales será tratado también en el apartado IV, relativo a las críticas sobre la Teoría Cosmopolita. 
dades sociales mundiales que está creando. Una globalización hegemónica que, en definitiva, trata de sustituir al ciudadano por un mero consumidor (Rifkin, 2004).

Para los cosmopolitas, es imprescindible que se avance hacia una protección mayor de los derechos fundamentales, hacia un compromiso con el desarrollo y bienestar de la población mundial, así como también que se respeten los recursos naturales y el medio ambiente. Esta corriente no entiende que la situación actual de globalización económica vaya a conducir al fin de la política ni al fin de la historia, sino que aún es posible avanzar hacia una globalización «humanizada». Esta visión cosmopolita de la globalización acepta y apoya la creciente interconexión e interdependencia mundiales, pero lucha en contra de que estas nuevas relaciones sólo sean guiadas por intereses económicos que, en última instancia, minimizan la posibilidad de regulación y de control de los distintos Estados nacionales.

La Teoría Cosmopolita se aparta de la concepción de la globalización como un proceso únicamente económico y destaca como características del proceso globalizador actual las siguientes. En primer lugar, se trata de un proceso multidimensional es decir, en este caso, el proceso de interconexión, de «intensificación de las dependencias recíprocas» (Beck, 1998: 77) que no se reduce al mercado mundial sino que se habla también de globalización ecológica, cultural, social y política ${ }^{24}$.

En segundo lugar, este proceso globalizador también es definido como un proceso artificial por la mayoría de autores -cosmopolitas y próximos a los movimientos antiglobalización- salvo Richard Falk, que entiende que la dinámica actual se debe a un proceso espontáneo (2002: 51), y Manuel Castells, para quien la globalización es el resultado inevitable de la revolución de las tecnologías de la información (citado en Santos, 2005: 260). John Gray también considera que la globalización es un proceso histórico (2000: 75). Para los defensores de la artificialidad de la globalización, ésta se ha desencadenado como consecuencia del desarrollo de la economía mundial, la tecnología, el incremento de las comunicaciones y, por tanto, no como efecto del proceso natural de evolución de la especie humana. Desde la corriente neoliberal se afirma que la globalización se presenta como un proceso espontáneo, automático, inevitable e irreversible. Este hecho, para Boaventura de Sousa Santos, consiste en una falacia, ya que esta corriente de

${ }^{24}$ Dentro de los autores que comparten la multidimensionalidad de la globalización se encuentran Bhagwati, 2005 -aunque en su libro se centre, sobre todo, en la globalización económica reconoce esta característica de la globalización actual-; Casadei, 2005: 27 -autor ajeno a la corriente cosmopolita-; Castells, Giddens y Touraine, 2001: 94, 75 y 99, respectivamente -cosmopolitas-; Boys, 2004: 153; Faria, 2001: 49; Fariñas, 2005: 35; Hsiao en Berger y Huntington, 2002: 65; Monereo en Monereo, Riera y Valenzuela, 2002: 118 -autores ajenos a la corriente cosmopolita-; Santos, 2005: 236 -cosmopolita-. 
pensamiento transforma las causas de la globalización en efectos de ésta (2005: 260) ${ }^{25}$.

En tercer lugar, otra característica muy controvertida de la globalización actual es determinar si es un proceso reversible o irreversible. La opinión más generalizada entre la doctrina cosmopolita es la del carácter irreversible de la globalización, pero sin desistir en la creencia de que sí es posible controlar los efectos negativos provocados por el proceso actual ${ }^{26}$. Por lo tanto, estos autores consideran que «la globalización está demasiado ampliamente aceptada y arraigada como para que su impacto integrador fundamental sea reversible» (Falk, 2002: 205). Sin embargo, Ralf Dahrendorf considera que el proceso de globalización actual sí puede ser reversible porque no es imposible que las barreras eliminadas después de 1989 pudiesen reaparecer con una nueva modalidad en otros lugares (2005: 35). Al margen de la corriente cosmopolita, Manuel Monereo (en Monereo, Riera y Valenzuela, 2002: 118) también comparte la creencia de que la globalización es, en muchos sentidos, reversible.

Boaventura de Sousa Santos da un paso más que los autores anteriores, ya que para él esa «otra» globalización ya se está construyendo. Así, tanto a través del cosmopolitismo como a través del patrimonio común de la humanidad, se está construyendo una globalización política alternativa a la hegemónica, «desarrollada a partir de la necesidad de crear una obligación política transnacional correspondiente a la que hasta ahora vinculó mutuamente a ciudadanos y Estados-nación. Esta obligación más amplia es por ahora meramente coyuntural, toda vez que todavía queda por concretarse (o imaginarse) una instancia política transnacional correspondiente al Estadonación» (2005: 280). El desarrollo de ambos conceptos en la práctica ha encontrado grandes resistencias desde las instancias pertenecientes y defensoras de la globalización hegemónica y se mantienen, por ello, en constante interacción y evolución (2005: 280 y 281).

${ }^{25}$ La artificialidad del proceso de globalización es defendida por Attinà, 2001: 161; así como por el cosmopolitismo (Beck, 2002: 49) que destaca sobre todo la artificialidad del concepto y afirma que este proceso se retroalimenta de la utilización de dicho concepto con el que se autocalifica, es decir, como lo denominan la globalización económica actual que lo creó; Giddens, 2000: 26; Held, 2005, 105. Estos dos últimos autores hacen referencia al hecho de que la globalización política tiene su origen en la globalización económica y en el surgimiento de problemas a escala global ante los cuales los Estados nacionales se muestran disfuncionales. Desde la corriente de izquierdas, M. ${ }^{a}$ José Fariñas, autora próxima a los movimientos antiglobalización, afirma que la globalización neoliberal actual es una construcción ficticia, es una ideología en sí misma y no un proceso histórico natural, que oculta los grandes problemas sociales y económicos que ella misma origina (2005: 36).

${ }^{26}$ El carácter irreversible del proceso de globalización es respaldado por Beck, 1998: 163; 2002. a: 61 y 2005; Domingo, Rafael en Caicedo, Domingo, Santiváñez (coordinadores); 2006: 22 y 25; Falk, 2002: 205. 


\section{Cosmopolitismo «desde arriba»}

\subsection{La constitución del Estado cosmopolita}

David Held define al «modelo cosmopolita de democracia» o «modelo cosmopolita de autonomía democrática» como «(...) un sistema de gobierno democrático que se organiza a partir de la diversas condiciones e interconexiones de las diferentes naciones y poblaciones y que se adapta a ellas» (1997: 174). Esta nueva forma de organización social y política debe ser entendida como una respuesta a la globalización basada en el principio de la indiferencia nacional del Estado y como la nueva forma de organización que auspicia la coexistencia de identidades nacionales según el principio de tolerancia constitucional ${ }^{27}$.

Entrando ahora a desarrollar el concepto de Estado cosmopolita, como paso previo a un análisis posterior, más exhaustivo, comenzaremos con una delimitación conceptual negativa. ¿Qué no debe entenderse por Estado cosmopolita? Primero, un Estado cerrado sobre sí mismo y ajeno a los problemas de la comunidad internacional. La política de un Estado cosmopolita debe ser inclusiva con respecto al otro -ya sea otro Estado, un pueblo, una organización internacional de cualquier tipo o un individuo-. Superando, por tanto, el nacionalismo metodológico, como ya dijimos al comienzo del presente artículo.

Segundo, el Estado cosmopolita no puede seguir los dictados de la globalización económica actual, sino que debe recuperar el concepto de «Estado de Bienestar» e intentar desarrollar una regulación jurídica que controle, en la medida de lo posible, los efectos negativos del mercado global. En este momento, puede que sea necesario destacar que la corriente cosmopolita considera que el Estado de Bienestar está en grave peligro para llevar a cabo las actividades que le son propias. Esta situación tiene lugar, principalmente, por las transformaciones recientes del capitalismo ${ }^{28}$ mundial que han alte-

${ }^{27}$ El principio de indiferencia nacional significa que dentro del Estado cosmopolita los conceptos «Estado» y «nación» estarán separados, es decir, en un Estado cosmopolita tendrán cabida múltiples naciones. Esta situación se garantizará mediante el principio de tolerancia constitucional ya que se garantizará la coexistencia, pacífica y en términos de igualdad, de las diversas identidades nacionales. Definiciones tomadas de Beck, 2004: 141 y 142.

${ }^{28}$ A juicio de Boaventura de Sousa Santos, las principales transformaciones que han provocado la crisis del Estado social son: la transformación de la economía por las empresas multinacionales, el aumento del desempleo estructural, el aumento la movilidad y la consecuente deslocalización de los procesos productivos, el aumento de la segmentación de los mercados de trabajo, la saturación del consumo por el consecuente desarrollo de una cultura de masas consumista, la caída vertical de la oferta pública de los bienes colectivos, la destrucción ecológica y el aumento considerable de los riesgos contra los cuales los seguros adecuados son inaccesibles para la mayoría de los trabajadores (2005: 201 y 202). Para $\mathbf{M}^{\mathrm{a}}$ José Fariñas (2005: 135) y John Gray (2000: 103) la superación del Estado social se debe a las transformaciones impuestas desde los mecanismos supraestatales de gestión de la globalización neoliberal económica 
rado sustancialmente las condiciones normales de producción de la sociedad y que, en última instancia, le han restado importancia al espacio-tiempo nacional; la globalización de la economía imperante y el incremento de poder de las empresas transnacionales; así como, por la adopción de políticas cada vez más liberales por parte de los Estados nacionales, por ejemplo, las privatizaciones masivas y la flexibilización de la normativa laboral, entre otras $^{29}$.

Tercero, el Estado cosmopolita no debe obviar o, incluso, no debe intentar acabar con los Estados nacionales, ya que la idea de un gobierno mundial unitario es «ilusorio» (Beck, 2004: 145). Por lo tanto, el Estado cosmopolita se presenta como un modelo híbrido en el que se fusionan características fundamentales que parecían excluirse entre ellas en los esquemas jurídicopolíticos anteriores.

En este nuevo panorama de organización de la actividad política, los Estados nacionales dejarán de ser los únicos centros de poder legítimos dentro de sus propias fronteras. A éstos, se sumarán los centros de decisión local, regional, transnacional e internacional. Los Estados nacionales serán «reubicados» (Held, 1997: 278) y estarán sujetos en sus actuaciones a un derecho cosmopolita de carácter democrático, es decir, el poder del Estado nacional sufrirá un proceso de transnacionalización y se multiplicarán los centros de poder para la toma de decisiones.

El desarrollo de esta construcción teórica tendrá como consecuencia un cambio en la concepción de la soberanía nacional y, por tanto, se deberá desarrollar una soberanía cosmopolita. Esta nueva concepción de la soberanía política tendrá como efecto que los Estados nacionales cederán parte de su soberanía a los centros de decisión política, y así, ésta superará su carácter territorial e indivisible. En este momento, la propuesta cosmopolita puede resultar contradictoria debido a la afirmación de que, por un lado, los Estados nacionales deberán ceder parte de su soberanía aunque, por otro lado, se señala que una de las causas de su debilidad actual es su pérdida de soberanía. Esta contradicción queda salvada porque, para la Teoría Cosmopolita, la cesión voluntaria de soberanía por parte de los Estados nacionales al Estado cosmopolita no significa una pérdida aún mayor de su poder político, sino que reforzará su posición ante los problemas globales y mejorará su relación con los ciudadanos ya que, de este modo, por medio de dicha cesión voluntaria, los Estados nacionales agrupados serán capaces de responder a sus necesidades sociales actuales y de solucionar de forma más eficaz los pro-

${ }^{29}$ Para una introducción al origen, el desarrollo y la crisis del Estado social en la línea expuesta en el presente artículo, véanse Gallego Méndez en Del Águila, 2003: 107 a 138; Olivas, 2004: 93 a 112. Sobre el aspecto concreto de la crisis actual del Estado del bienestar, véase Bauman, 2001b: «3. Los extraños de la era del consumidor: del Estado del bienestar a la prisión», 49 a 61 . 
blemas globales ${ }^{30}$. Esta reflexión, necesaria para los Estados nacionales, debe entenderse como un proceso de autorrenovación de éstos que les permitirá controlar y gestionar de forma eficaz la realidad globalizada. Por tanto, el Estado cosmopolita no debe entenderse como un Estado nacional ampliado, sino que, por medio de una soberanía compartida entre los distintos Estados nacionales y la cooperación transnacional surgida entre ellos, por medio de la integración en el seno del Estado cosmopolita, se protegerán los derechos civiles y la democracia a escala mundial. Por tanto, es inherente al Estado cosmopolita su carácter democrático.

David Held (1997: 271 y siguientes), en este sentido, propone un derecho democrático cosmopolita y una comunidad democrática cosmopolita para el pleno desarrollo del Estado cosmopolita. En primer lugar, este derecho cosmopolita, diferente tanto del derecho nacional como del derecho internacional, debe asegurar un derecho público democrático a toda la humanidad y ser reconocido por los Estados nacionales democráticos. Su principal objetivo debe ser garantizar por medio de todo tipo de normas jurídicas las libertades civiles y la multiplicidad cultural en todos los niveles -local, regional, nacional y global-. Este derecho será también la principal fuente de la soberanía compartida, es decir, de la soberanía cosmopolita. Esta necesaria cosmopolitización del derecho plantea grandes retos debido a la situación internacional actual.

En segundo lugar, la comunidad democrática cosmopolita debe agrupar en su seno a una comunidad internacional de Estados nacionales y sociedades democráticas que respalden este derecho democrático cosmopolita tanto dentro como fuera de sus territorios nacionales.

En esta aproximación al Estado cosmopolita se observa la necesidad de una renovación conceptual, como mínimo, de los elementos constitutivos clásicos del Estado nacional para que éstos puedan tener su reflejo en el supuesto de que se institucionalice un Estado cosmopolita democrático mundial.

\subsection{Elementos constitutivos del Estado cosmopolita}

\subsubsection{TERRITORIO: ESPACIO TRANSNACIONAL}

En este contexto se abre un nuevo espacio transnacional donde debe entrar el derecho cosmopolita a regularlo. En este nuevo escenario, los actores estatales pierden su papel hegemónico en el plano internacional y de-

30 «Los Estados nacionales encarnan el Estado de congelación de lo político, un Estado del que se puede salir mediante estrategias reflexivas de autovivificación y redeterminación de lo político» (Beck, 2004: 233). Para superar la situación actual en la que se encuentran los Estados nacionales, Beck (2004: 234 a 311) propone una serie de estrategias políticas de reflexión para los Estados nacionales como pasos necesarios para hacer frente a los procesos más negativos de la globalización. 
berán también aceptar a los actores no estatales en este ámbito de actividad. En el actual espacio transnacional irregulado, se presenta al Estado cosmopolita, por un lado, como la única respuesta posible a la globalización descontrolada y, por otro lado, como la única entidad política capaz de solucionar la situación de disfuncionalidad de los Estados nacionales.

El espacio transnacional, que se acaba de mencionar, se encuentra en el ámbito existente entre las regulaciones de los Estados nacionales -relaciones entre los ciudadanos y un Estado nacional determinado- y el derecho internacional -relaciones entre los distintos Estados nacionales- (Held, 2005: 214). Este espacio está siendo ocupado por multitud de normas jurídicas, elaboradas por organismos tales como las redes transnacionales, por las nuevas organizaciones supranacionales y por las empresas transnacionales, es decir, sobre todo por intereses privados con escasa o nula legitimidad democrática $^{31}$.

La conveniencia de expandir la actividad política al espacio transnacional por medio del Estado cosmopolita ha sido presentada, sobre todo, como respuesta a la disfuncionalidad de los Estados nacionales en su respectiva competencia de control territorial nacional. La Teoría Cosmopolita afirma que las fronteras nacionales son cada vez más permeables para agentes externos, principalmente, por el desarrollo de la globalización económica, cuyos principales actores son las empresas transnacionales, y el establecimiento de unos medios de comunicación que actúan globalmente. En torno a la debilidad del aspecto «territorial» de los Estados nacionales, Ulrich Beck afirma que, debido a la superación de las fronteras nacionales, nos encontramos en un nuevo sistema transnacional. El anterior sistema internacional se caracterizaba, entre otros aspectos, porque las fronteras de los Estados nacionales mantenían su carácter constitutivo, pero en la actualidad esta característica ha sido superada (2004: 205). El debilitamiento de las fronteras para la circulación de capitales a nivel global no tiene un desarrollo paralelo en la libertad de circulación de los seres humanos, sus derechos y sus culturas. Éstos están sometidos de forma desigual como lo demuestra la inmutable vinculación existente entre la ciudadanía y la nacionalidad, que impide el acceso a los derechos a aquellos que carecen de estatus jurídico de nacionales de un Estado. «El concepto de globalización, y su consecuencia inmediata, la desterritorialización, deberían ser considerados, entonces, como una parte de la teoría del imperialismo o, simplemente, como unos eufemismos, tras los cua-

${ }^{31}$ Para un análisis sobre el desarrollo transnacional del derecho en campos de actividad determinados como el comercio internacional, la banca internacional, etc. véanse Caicedo, Aparicio; Domingo, Rafael y Santiváñez, Martín (coordinadores), 2006; Wiener, 1999. Aunque ambos autores no se encuentran dentro de la corriente de pensamiento cosmopolita, es necesario advertir que este hecho se debe a que el debate en torno al desarrollo de un derecho transnacional se produce en la mayor parte de la doctrina científica jurídica y no sólo en el seno de esta Teoría. 
les se esconden conocidas y viejas prácticas imperiales de dominación» (Fariñas, 2005: 143) 32 .

\subsubsection{PueBlo: SOCIEDAD CIVIL COSMOPOLITA}

La comunidad de ciudadanos nacionales o la sociedad nacional, para parte de la doctrina internacional entre la que se encuentran los autores de la corriente cosmopolita, está inmersa en un proceso de redefinición.

Según Anthony Giddens, hay que huir del concepto tradicional de sociedad para poder distinguirla de los Estados nacionales y de la identidad (en Castells, Giddens y Touraine, 2001: 48). Cuando se habla de crisis de la sociedad, se hace en el siguiente sentido. La sociedad que ahora se disuelve, la sociedad que está desapareciendo, es la que fue definida y construida por el Estado-nación. En el mundo actual, en el que los flujos migratorios son tan elevados, el concepto de ciudadanía está cambiando y el concepto de «ciudadanía nacional» resulta obsoleta para garantizar unos derechos mínimos universales a esta nueva «ciudadanía de la movilidad» (Rifkin, 2004: 351).

Para explicar la nueva estructura social, Manuel Castells (en Castells, Giddens y Touraine, 2001: 53) propone el concepto de «sociedad red». Este concepto intenta superar la terminología de sociedad de la información o sociedad postindustrial. «La sociedad red es una estructura social formada por redes de información alimentadas por las tecnologías de la información características del paradigma internacional» (en Castells, Giddens y Touraine, 2001: 131). Las redes están formadas por nodos que siguen una lógica binaria de inclusión-exclusión. Todo lo que está en la red es necesario para que la sociedad exista, pero todo lo que no está en la red no existe para la sociedad. La economía global, las sociedades, las expresiones culturales, todo se está transformando con la lógica de la interconexión ${ }^{33}$. Sin embargo, José Eduardo Faria augura una «sociedad de organizaciones» en la que los individuos se agruparán atendiendo, básicamente, a las organizaciones de las que formen parte. Por tanto, para José Eduardo Faria, atendiendo a la evolución y a los cambios sufridos por los individuos, podría llegar un momento en el que pasaríamos a formar parte de una «sociedad de individuos», a constituir una «sociedad de organizaciones», es decir, que los individuos tomarían como referencia para desarrollar una vida social las organizaciones a las

${ }^{32} \mathrm{El}$ debilitamiento de las fronteras nacionales no es una opinión mantenida únicamente desde la corriente cosmopolita -Held, 2005: 123; Santos, 2005: 347-, sino que también es afirmado por Del Águila Teserina en Oliet Palá, 2003: 202; Faria, 2001: 14, 44; Hunter y Yates en Berger y Huntington, 2002: 388; Huntington, 1997: 37; Olivas, 2004: 50; Touraine, 2005: 257; Rifkin, 2000: 296 y 2004: 280.

${ }^{33}$ Para más información sobre la sociedad red véanse Castells, 2003: Vol. I; Castells en Castells, Giddens y Touraine, 2001: «Algunos elementos de teoría social general», 131 a 167. 
que pertenecen. Los individuos -integrantes de distintas organizaciones, los hombres organizacionales- actuarían según los dictados de tales organizaciones que, en última instancia, propondrían sus metas y objetivos según los dictados de la economía globalizada. Esta situación tiene como principal consecuencia una fragmentación de la ciudadanía y la mayor dificultad del Estado nacional para hacer prevalecer el interés público sobre los distintos intereses específicos (2001: 138 a 149). Es de una opinión similar Fernando Vallespín, ya que afirma que la sociedad nacional está sufriendo un proceso de fragmentación, es decir, según sus diversos intereses individuales, los ciudadanos están abandonando las identidades nacionales, individuales y cívicas y se está desarrollando un proceso de «corporativización social» (en Oliet Palá, 2003: 156).

Richard Falk distingue entre sociedad civil global y sociedad civil transnacional. De hecho, este autor se inclina por la primera, ya que el término transnacional sigue sujeto o sugiere de una forma más directa a la lógica del modelo nacional de organización política y no supera la división fronteriza existente que debe dejar paso al desarrollo de una sociedad global para una aldea global (2002: 200). Siguiendo en esta línea superadora de las divisiones nacionales excluyentes, David Held (2005: 152 a 154) aporta un término novedoso y habla de «ciudadanía multinivel». Con este concepto quiere hacer referencia a la necesidad existente en la actualidad de identidades nacionales incluyentes. El desarrollo de la actividad política en la era de la globalización conlleva la participación de los ciudadanos en distintos entes políticos de distintos niveles. Compartiendo las tesis de David Held (1997 y 2005) y Richard Falk (2002), Gerard Delanty (2000) relaciona la crisis de los Estados nacionales, así como la evolución del concepto de ciudadanía, desde un punto de vista cosmopolita. Éste desarrolla un análisis del concepto de ciudadanía ${ }^{34}$ y llega a la conclusión de que en la situación actual no puede hablarse de uniformidad respecto al término ciudadanía, sino que deben respetarse las diferencias y para ello propone una participación multinivel. La política se desterritorializa y deben seguir garantizándose los mismos derechos para todos los individuos. Con este nuevo panorama político encajan tanto el concepto de ciudadanía multinivel como la idea de una sociedad global. Siguiendo la terminología de Guy Boys (2004: 28), debido al proceso de mundialización, estamos asistiendo al nacimiento de una sociedad postmoderna con estructuras novedosas en relación con las anteriores sociedades nacionales ${ }^{35}$.

${ }^{34}$ El análisis de la ciudadanía desarrollado por Gerard Delanty (2000) no sólo se centra en la ciudadanía cosmopolita, sino que estudia la evolución del concepto de ciudadanía a lo largo de la historia.

${ }^{35}$ Aunque todas estas aportaciones son construcciones diferentes para definir la sociedad, todos los autores comentados dan por superada la capacidad del Estado nacional para agrupar bajo su amparo a la sociedad nacional sin necesidad de que ésta busque otro tipo de institución organizadora. 
Las sociedades nacionales, cada vez más interconectadas con el exterior, superan el contenedor nacional dando paso al surgimiento de una sociedad civil transnacional ${ }^{36}$, esto es, el proceso de globalización está dando como resultado el nacimiento de una nueva sociedad mundial ${ }^{37}$. Junto a la sociedad nacional, aparece una sociedad mundial que se compone de actores transnacionales de muy diversa índole. La principal consecuencia de esta situación es que «en el campo de acción de la sociedad mundial estamos asistiendo a una politización mediante la despolitización de los Estados» (Beck, 1998: 147). «El concepto de "sociedad nacional" cada vez se topa más con la evidencia de una básica disminución de etiquetas: lo que aparece y se marca como nacional es en realidad más o menos transnacional o cosmopolita» (Beck, 2002a: 181). La agrupación de los miembros de las sociedades nacionales en otros movimientos independientes de los Estados nacionales hace que éstos se debiliten ${ }^{38}$.

Dentro de la emergente sociedad civil transnacional y con un carácter marcadamente sectorial, influida por la expansión de la economía a nivel global, está emergiendo una clase capitalista transnacional que impone sus derechos y sus mecanismos hegemónicos de actuación. M. ${ }^{a}$ José Fariñas la define como una nueva forma de dominación social. Boaventura de Sousa Santos afirma que esta nueva clase social se institucionaliza por medio de las empresas transnacionales ${ }^{39}$.

La Teoría Cosmopolita «desde arriba», de este modo, basa su propuesta en una sociedad civil activa y liberada de las fronteras territoriales. Debe surgir una sociedad civil global que otorgue legitimidad al Estado cosmopolita ${ }^{40}$.

${ }^{36}$ Para una introducción sobre esta cuestión véase Garrigues Walker, Antonio en Caicedo, Domingo y Santiváñez (coordinadores), 2006: «La hora de la sociedad civil », 17 a 20.

${ }^{37}$ Esta opinión es mantenida por Beck, 1998 y 2002b; Held, 2005: 152 a 154; Falk, 2002: 241. La aparición de una sociedad civil global es entendida todavía más como un desafío o un objetivo a lograr que como una realidad. En relación con Ulrich Beck, este autor desarrolla un análisis sobre la sociedad civil global actual y su relación con el riesgo tanto presente como futuro como consecuencia de un desarrollo tanto económico como tecnológico descontrolado. Para conceptualizar esta situación el autor emplea el término de «sociedad de riesgo» (2002b).

${ }^{38}$ Esta afirmación encaja con la idea de que la sociedad nacional se está viendo superada por la redistribución de los individuos que la forman en un nuevo conglomerado de actores. Estos últimos han surgido gracias a la globalización, al desarrollo de los medios de comunicación y a la creciente interconexión mundial, y entre ellos podemos encontrar a las asociaciones civiles transnacionales, también las organizaciones no gubernamentales internacionales, así como la sociedad red de Manuel Castells y la identidad organizacional o sociedad de organizaciones propuesta por José Eduardo Faria.

${ }^{39}$ Esto es reconocido por Fariñas, 2005: «11. La nueva «clase capitalista global: los globalistas», 125 a 128; Santos, 2005: 241 y 242.

${ }^{40}$ El debate y la importancia de la sociedad civil global también es aplicable y de gran importancia para el desarrollo de la propuesta del cosmopolitismo «desde abajo». Por tanto, en el apartado siguiente del presente artículo téngase en cuenta lo dicho aquí respecto a ésta. 


\subsubsection{PODER NACIONAL: RENOVACIÓN CONCEPTUAL}

La propuesta de la corriente cosmopolita «desde arriba» desarrolla una renovación conceptual de los conceptos de poder y de soberanía ${ }^{41}$. Por poder entenderemos aquella potestad propia de los Estados nacionales que es inherente a la propia institución y que les permite influir en la conducta de sus ciudadanos, incluso, por medio del uso de la fuerza.

La conveniencia de la renovación conceptual de poder surge de la siguiente reflexión. Como ya se ha apuntado, según la Teoría Cosmopolita, el poder del Estado nacional delimitado territorialmente se encuentra en crisis. Esta circunstancia se está produciendo como consecuencia del proceso de globalización y sus efectos en las instituciones políticas nacionales, así como por la proliferación de instituciones internacionales, transnacionales y/o locales que adoptan decisiones al margen de la política nacional y de la política internacional ${ }^{42}$.

El poder, en el sentido clásico del término, está sufriendo un proceso de reubicación, más allá de las instituciones nacionales y de la demarcación territorial del Estado nacional. Esto es, el poder del Estado nacional se desterritorializa y se encuentra inserto en «flujos» que circulan más allá del control institucional nacional. Esta nueva ubicación del poder de los Estados nacionales ha permitido, incluso, que parte de dicho poder se encuentre ahora también en redes transnacionales, en organizaciones no gubernamentales o en movimientos sociales. Esta nueva ubicación del poder en «flujos» es utilizada por Manuel Castells y se refiere a la situación que venimos comentando. El Estado nacional ha perdido el control sobre el poder. Éste ya no se limita a la demarcación territorial propia de cada Estado, sino que se distribuye en nuevas instituciones y sus consecuencias se expanden a nivel global (en Castells, Giddens y Touraine, 2001: 93 ${ }^{43}$. Esta misma situación

${ }^{41}$ Esta serie de conceptos que aquí analizaremos de forma «cosmopolita» están siendo debatidos por la doctrina científica. Este debate se debe a que las distintas corrientes de pensamiento que estudian la globalización y sus efectos, la crisis democrática, el papel de los Estados nacionales en la comunidad internacional y ante los nuevos agentes no estatales, entre otros muchos temas de actualidad, aportan un significado distinto o, al menos, matizado sobre estos conceptos. Por su excesiva extensión, en el presente artículo nos centramos en la visión cosmopolita de tales conceptos, pero es necesario advertir sobre la dialéctica doctrinal existente a su alrededor, no sólo dentro del ámbito de la corriente cosmopolita.

${ }^{42}$ Esta nueva situación es reconocida y analizada por Appadurai, 2001: 175; Beck, 1998: 153 y 2004; Faria, 2001: 92 y 93; Held, 2005, 123; Oliet Palá, 2003: 9; Olivas, 2003: 50. La desterritorialización del poder debido a causas económicas es apuntada por Fariñas, 2005: 139 y 141. Para esta autora, el poder ya no se identifica espacialmente, sino por una acumulación de capitales sin límites espaciales que tiene como consecuencia una multiplicación de los centros de poder.

${ }^{43}$ Para más información sobre esta idea véase Castells, 2003: Vol. I, «6. El espacio de los flujos», 453 a 506 . 
es denominada por David Held con el concepto de «redes» de empresas, ciudadanos, sindicatos, ONG, que ahora comparten con los Estados nacionales parte del poder de estos últimos (2005: 108). En determinados casos, son los propios Estados nacionales los que han delegado poder en estos entes políticos locales, regionales o supranacionales (Huntington, 1997: 37). Véase, como ejemplo paradigmático, la Unión Europea.

Ante esta nueva ubicación del poder, surgen varios problemas importantes. Por un lado, la disolución de la unidad del poder político tiene como principal consecuencia la disfuncionalidad ante nuevos problemas sociales. Por otro lado, la imposibilidad de control de éste tal y como se desarrollaba en el seno de los distintos Estados nacionales. Esta nueva situación de imposibilidad de control del poder nacional conduce, a los autores cosmopolitas, a la convicción de que también las democracias nacionales actuales están en crisis.

En la era global, la toma de decisiones no sólo se está alejando del ámbito de decisión de los Estados nacionales y se está trasladando a entidades supranacionales o internacionales, a organizaciones no gubernamentales y a empresas transnacionales, sino que también se están desarrollando procesos locales de toma de decisión política con lo que la mediación entre Estado nacional y ciudadanos, mediante la participación política, se está diluyendo en un proceso de toma de decisión «ademocrático» fomentado por el desarrollo de los medios de comunicación electrónicos y su uso electoralista por parte de los grupos políticos ${ }^{44}$. Sin embargo, dentro de la corriente cosmopolita, Boaventura de Sousa Santos (en Santos y Garavito, 2007: 280) es contrario a afirmar que la democracia se encuentre en una situación de crisis. Argumenta dicha afirmación en la condicionalidad política de la democracia para recibir financiación de las instituciones financieras internacionales. Asume los cambios que ha sufrido la democracia; dichos cambios han sido considerados en líneas precedentes como justificativos de la crisis, pero para este autor sólo suponen la adecuación de la democracia al nuevo contexto impuesto por la globalización hegemónica. Ante dicha situación, se ha registrado una oposición, sobre todo, desde las prácticas políticas de base popular en el Sur del globo. M. José Fariñas (2005), por el contrario, sí afir-

\footnotetext{
${ }^{44}$ Con la utilización del concepto «ademocrático» intento hacer un paralelismo con el concepto jurídico de alegalidad. Es decir, en la crisis de la democracia representativa, por el desarrollo de los medios de comunicación, se presentan situaciones provocadas, incluso, por los grupos en el poder que se desarrollan sin una regulación específica debido a que los avances tecnológicos van a mayor velocidad que los desarrollos legislativos del Estado nacional. En estos casos, los grupos políticos deberían sopesar con mayor profundidad las posibles consecuencias de su actividad política. Esta reflexión es compartida por Faria, 2001: 26 y 27. El problema sobre el control democrático del desarrollo institucional global también es analizado por Boys, 2004: «C) El aspecto político: la des-sustancialización de democracia», 44 a 49; Dahrendorf, 2002: 7 a 15.
} 
ma que la democracia se ha debilitado en la medida en que se ha supeditado a las exigencias del mercado de capitales global. Las características del neoliberalismo económico actual impiden el desarrollo de cualquier tipo de democracia de carácter social, cultural y económico que priorice las características participativas, deliberativas y emancipadoras de la ciudadanía ${ }^{45}$.

Un concepto relacionado con el poder es, también, el concepto de soberanía. Este término debe hacer frente a dos realidades. Por un lado, el concepto tradicional de soberanía, según la Teoría Cosmopolita, se encuentra en un proceso de redefinición. Por otro lado, dicha Teoría ha desarrollado conceptos novedosos de soberanía para amoldar la nueva situación postnacio$n a l^{46}$.

Atendiendo a la supuesta crisis del concepto de soberanía, es necesario destacar que la concepción de soberanía como un poder público ilimitado e indivisible resulta obsoleta y los Estados nacionales, debido al cúmulo de causas mencionadas con anterioridad, se encuentran, si no formalmente, sí materialmente, limitados en su autoridad decisoria ${ }^{47}$. La puesta en cuestión de la soberanía del Estado nacional se lleva a cabo por distintos actores: 1) por las empresas multinacionales debido al poder económico adquirido por la economía globalizada; 2) por las organizaciones no gubernamentales, dotadas de una gran capacidad de movilización social ante problemas nacionales que ellas consideran de tal entidad como para que se les preste una atención mundial; 3) por el creciente poder de movilización e influencia de los individuos gracias al desarrollo de los medios de comunicación (Hunter y Yates en Berger y Huntington, 2002: 388). En cuanto a las nuevas conceptualizaciones del término «soberanía», la Teoría Cosmopolita maneja, sobre todo, los siguientes: soberanía incluyente, soberanía excluyente, soberanía nacional, soberanía transnacional; necesitan ser analizados como paso previo a tratar la distribución del poder en los Estados cosmopolitas. En primer lugar, la soberanía nacional «se refiere al derecho del Estado de gobernar sobre su territorio delimitado» (Held, 1997: 130), al igual que la soberanía excluyente.

Por el contrario, la soberanía incluyente «significa que la renuncia a derechos de soberanía va de consuno con la adquisición de poder político

\footnotetext{
${ }^{45}$ Para más información sobre la posición de esta autora véase Fariñas, 2005: «3. La democracia formal y liberal»: 77 a 83 .

${ }^{46} \mathrm{La}$ necesidad de reformular el concepto de soberanía nacional y avanzar hacia una soberanía cosmopolita ha sido comentado brevemente en el apartado «1.1. La constitución del Estado cosmopolita», pero parece oportuno retomar aquí esta cuestión y profundizar en ella un poco más.

${ }^{47}$ Esta opinión es mantenida por Held, 1997: 169; Faria, 2001: 22; Fariñas, 2005: 140. Para algunos autores, no cosmopolitas, la pérdida de soberanía del Estado nacional es de tal entidad, que llegan a afirmar que dicha institución, en la actualidad, es solamente una de las varias instituciones organizadoras de la sociedad: Guéhemo, 2000: 42; Faria, 2001: 129.
} 
configurador, en virtud de la cooperación transnacional. Pero esto sólo puede conseguirse si se concibe y configura la globalización como proyecto político» (Beck, 1998: 187 y 188). Este significado coincide también con el concepto de soberanía transnacional.

Por último, David Held añade otro concepto más que nos ayudará también a clarificar el concepto de soberanía, la autonomía. Este último término «denota el poder real con el que cuenta un Estado-nación para articular y llevar a cabo sus metas políticas de forma independiente» (1997: 130), es decir, el poder efectivo de un Estado nacional para desarrollar sus competencias de forma independiente y sin necesidad de colaboración para obtener una gestión eficaz. Con esta distinción entre autonomía y soberanía se quiere distinguir terminológicamente dos situaciones que se producen de facto, aunque la última de ambas no tiene reflejo en los ordenamientos jurídicos nacionales. Por un lado, están aquellas materias cuya competencia el Estado nacional ha cedido a entes supranacionales, para que sean gestionadas y reguladas desde aquéllas. Esta cesión voluntaria de soberanía es regulada dentro del marco del ordenamiento jurídico nacional, así como en el marco jurídico de dicha organización supranacional. Por otro lado, en cambio, hay otras materias sobre las cuales el Estado nacional continúa teniendo su competencia pero, de facto, ésta se encuentra en diversas instituciones políticas y/o económicas transnacionales ${ }^{48}$. La soberanía se erosiona cuando es desplazada por formas de autoridad más elevadas y/o independientes de los Estados nacionales, que recortan la base de legitimidad en la elaboración de decisiones en el marco nacional. Esta reducción de la soberanía del Estado nacional puede que, por otro lado, tenga consecuencias en las democracias modernas, y es necesario precisar si se ha producido por la creación y el desarrollo de redes de relaciones regionales y globales (Held, 1997: 130). Por ejemplo, las instituciones internacionales por medio de actos jurídicos, en algunos casos, restringen cada vez más la capacidad de actuación de los Estados nacionales en su propio territorio. También queda restringida la idea absoluta de soberanía territorial de los Estados nacionales por la necesidad de aceptar unos principios legítimos y universales ${ }^{49}$.

La pérdida de soberanía se ha producido de manera desigual. Así, los Estados más débiles encuentran amenazada su soberanía no sólo por los

\footnotetext{
${ }^{48}$ En este segundo caso, algunos autores consideran que el Estado nacional ha perdido, como mínimo, su autonomía. Tal es el caso de Held, 1997; Olivas, 2003: 45. Otros autores, no siguen esta distinción terminológica, pero sí reconocen que hay ámbitos en los que los Estados nacionales se muestran «materialmente limitados en su autoridad decisoria» (Faria, 2001: 22).

${ }^{49}$ El primer ejemplo es utilizado por Huntington, 1997: 37; Rodríguez Carrión en Oliet Palá, 2003: 279. El segundo ejemplo es empleado por Singer, 2003: 17. En ambos casos se quiere mostrar la pérdida de soberanía de los Estados nacionales por el desarrollo de un derecho internacional, de facto, vinculante.
} 
Estados más poderosos, sino también por las agencias financieras internacionales y los actores transnacionales privados (Santos, 2005: 248).

Después de lo analizado hasta el momento, debemos responder a una cuestión capital: ¿todos los problemas del Estado nacional actual se solucionan con el Estado cosmopolita? En principio, no ${ }^{50}$. El Estado cosmopolita debe tener un carácter subsidiario y regular sólo aquellas materias que escapen al control de los Estados nacionales y que necesiten de la cooperación transnacional para su gestión y solución. Esta reflexión reincide en la idea de que los Estados nacionales no serán superados por el Estado cosmopolita, sino que éste surgirá de una agrupación voluntaria de los Estados nacionales democráticos y no tratará de anular la actividad política de éstos. La soberanía será compartida por las múltiples instituciones existentes y éstas desarrollarán su actividad política según las competencias transferidas por aquélla. Para que esta situación tenga éxito en su desarrollo deberá contar con la elaboración de un derecho democrático cosmopolita que la regule ${ }^{51}$.

Para adecuarse a la realidad planteada, la soberanía debe desprenderse de su característica de indivisibilidad. Esta nueva formulación del concepto de soberanía tendrá como efecto primero que el Estado cosmopolita poseerá una soberanía compartida e inclusiva entre los distintos Estados nacionales. Esta nueva soberanía cosmopolita, según Ulrich Beck, «convergente y compartida no reduce la soberanía de los Estados particulares; al contrario, la potencia» (2004: 140).

\subsection{Regulación jurídica del Estado cosmopolita: democracia cosmopolita y derecho democrático cosmopolita}

Hablando en términos generales, la democracia cosmopolita es el modo de organización política de la postmodernidad que ayudará a los Estados nacionales a reubicarse ante esta nueva situación y a superar la crisis actual de la democracia. Esta democracia será desarrollada en el marco del Estado democrático cosmopolita. Como complementario del concepto anterior, el derecho cosmopolita es un derecho público de carácter democrático, que se encuentra en la zona de anomia existente entre los distintos derechos nacionales y el derecho internacional. El derecho democrático cosmopolita surge en el espacio transnacional y trasciende los intereses nacionales y los Esta-

\footnotetext{
${ }^{50}$ Esta opinión es compartida por todos los autores defensores de la Teoría cosmopolita analizados en el presente proyecto: Beck, 2004: 132 y 133; Castells, 2003: Vol. II, 397; Dahrendorf, 2005: 132; Held, 2005, 39 y 171; Megías, José J. en Caicedo, Aparicio; Domingo, Rafael y Santiváñez, Martín (coordinadores), 2006: «Una constante histórica. El derecho global», 29 a 32.

${ }^{51}$ Este aspecto de la propuesta cosmopolita ya ha sido apuntado en el apartado «1.1. La constitución del Estado cosmopolita», en el tercer punto de la delimitación conceptual negativa realizada sobre esta institución. Se ha considerado oportuno reiterarla aquí por su importancia en la construcción supranacional cosmopolita.
} 
dos y se extiende a todos los miembros de la «comunidad universal» (Held, 1997: 272).

Como reacción ante el desarrollo de un nuevo Estado cosmopolita y de una nueva forma de democracia, David Held (2005: 157 a 200) aboga por la creación de un nuevo pacto mundial. El pacto que elaboraron las distintas sociedades nacionales para la constitución de sus Estados nacionales es insuficiente para hacer frente a la necesidad de gobernanza global y la creación del Estado cosmopolita. Este nuevo pacto debe basarse en los principios socialdemócratas, pero con una aplicación universal, para garantizar la democracia y el bienestar a toda la población mundial. Este nuevo pacto exigirá que la soberanía nacional tome un impulso transnacional definitivo y se supere la regulación internacional vigente. Este pacto será, en definitiva, un pacto socialdemócrata global, que exigirá el compromiso, por parte de todos los Estados nacionales que lo acepten, para el mantenimiento de una soberanía compartida, de un régimen democrático supranacional y para la adopción de todos los compromisos necesarios en aras de solucionar los problemas incluidos en la agenda global. Con el fin de cumplir el objetivo anterior, será también necesario la creación de controles, para vigilar el cumplimiento de este nuevo derecho global y de los compromisos transnacionales adoptados, entre la agrupación de Estados nacionales democráticos que suscriban dicho pacto. De este modo, estos compromisos serán el origen de la democracia cosmopolita y la base para el desarrollo del Estado cosmopolita.

En este contexto de reflexión sobre la necesidad de dar un nuevo impulso a las democracias nacionales, Anthony Giddens aboga por una profundización de la propia democracia, es decir, «democratizar la democracia» (2000: 88). Esta nueva situación supondrá reformas en la política nacional para alcanzar un mayor grado de transparencia, así como una gestión más efectiva de los asuntos sociales, pero esta reforma no debe detenerse en los límites fronterizos de los distintos Estados nacionales, sino que debe avanzarse hacia una democratización a nivel mundial. Esta expansión de la democracia estará unida, en todo caso, al desarrollo de una sociedad civil mundial participativa, que luche activamente en esta dirección de cambio del panorama internacional contemporáneo.

Con la instauración del Estado cosmopolita, Ulrich Beck ${ }^{52}$ recoge una serie de efectos positivos que se producirían a nivel global. En primer lugar, los Estados nacionales ${ }^{53}$ se beneficiarían de un incremento de la sensación de

${ }^{52}$ Aunque se ha tomado de este autor la referencia general a los efectos positivos del cosmopolitismo, es necesario advertir que la relación entre éstos y su orden de preferencia no ha seguido los criterios del autor cosmopolita.

${ }^{53}$ En este momento debemos entender los Estados nacionales como son definidos desde la teoría cosmopolita, es decir, Estados que hayan superado el nacionalismo metodológico y la estrechez de miras nacional. Estados que hayan consentido un reparto de su soberanía y que respeten el derecho cosmopolita. 
poder. En segundo lugar, una ampliación real del espacio de poder en el ámbito de desarrollo de la actividad política y jurídica nacional. En tercer lugar, se produciría un ennoblecimiento de los problemas mundiales por su reconocimiento por parte de los Estados nacionales y del Estado cosmopolita. En cuarto lugar, la apertura de dominio y acción de los Estados nacionales a un espacio transnacional. Esta cuarta ventaja, junto con la anterior, tendría como efecto positivo combinado una gestión más eficaz y eficiente de los problemas reconocidos como globales. En este sentido, por ejemplo, se garantizaría el respeto de unos derechos humanos a nivel mundial (2004, 307 a 310).

\subsection{El Estado red}

Manuel Castells es el autor que desarrolla el concepto del Estado red ${ }^{54}$. Éste puede definirse como la unidad operativa real de la gestión política en un mundo globalizado, formado por Estados nacionales, organizaciones e instituciones internacionales, asociaciones de Estados nacionales, gobiernos regionales y locales y ONG.

El marco temporal en el que se desarrolla esta propuesta es el contexto postnacional -según los términos de Habermas (citado en Castells, 2003: Vol. II, 392)-. Este concepto coincide con el espacio temporal denominado postmoderno o segunda modernidad, dentro de la Teoría Cosmopolita. Por tanto, comparte marco temporal, así como la base conceptual y metodológica de partida, expuesta en la introducción para la corriente cosmopolita.

El punto de partida que toma para su construcción política es el que sigue. El nuevo sistema de poder, tal y como establece David Held, se caracteriza por la pluralidad de fuentes de autoridad o, incluso, por la pluralidad de fuentes de poder, siendo el Estado nacional sólo una de ellas.

En este contexto, para continuar con el hilo argumental del Estado red, es necesario entender que el poder estatal está constituido por un complejo patrón de alianzas y compromisos sociales. Este bloque de poder a nivel nacional puede no reproducirse a nivel de cada región o localidad. Por tanto, en relación con el bloque de poder, existe una diferenciación territorial del Estado. En el seno de esta segunda relación es donde se hace posible pensar en un nivel mayor de complejidad en las redes del gobierno constituidas por encima del Estado nacional y surge la imagen de un Estado nacional, inserto en el Estado red global.

Cuando el Estado nacional se vincula, bien con fragmentos de otros Estados, bien con asociaciones de Estados, se desarrolla el Estado red y «la práctica real del estado red se caracteriza por la tensión entre tres procesos

${ }^{54}$ El análisis del concepto del Estado red se basará en Castells, 2003: Vol. II, «5. La globalización, la identificación y el estado: ¿un estado impotente o un estado red?», 335 a 400. 
que están interrelacionados en las políticas estatales: cómo se relacionan los estados individuales con sus súbditos mediante la representación de sus intereses sopesados en el estado red; cómo aseguran el equilibrio y el poder del estado red al que pertenecen, en la medida en que éste aporta la plataforma que asegura la eficiencia del estado en un sistema globalizado; y cómo fomentan sus intereses específicos vis à vis los otros estados en su red compartida» (2003: Vol. II, 394 y 395). Este espacio político tridimensional constituye la realidad de la gobernanza global. ¿Cómo operan las relaciones de poder, en este proceso de gobernanza global? Para contestar a esta cuestión, Manuel Castells concluye que la única respuesta posible es proceder a un análisis empírico de las relaciones de poder existentes y la utilidad del esquema propuesto habrá de enjuiciarse en la práctica de tal análisis. Aun con la falta de este análisis empírico, el citado autor entiende que es posible decir que el sistema de toma de decisiones políticas basado en el Estado red se caracteriza por órdenes superiores de complejidad e incertidumbre. La definición de los objetivos de la gobernanza global, por ejemplo, la definición de lo que constituye un bien público, en ausencia de instituciones gubernamentales globales legítimas, depende de las relaciones de poder existentes en el estado red. Teniendo en consideración la complejidad asimétrica del Estado red, su estabilidad dependerá de que cada nodo de la red, es decir, cada una de los Estados nacionales que forme el Estado red, incluido el más dominante, asuma una pérdida de su soberanía individual.

En este momento de la construcción de Manuel Castells, se produce su «cosmopolitización». El hecho de que el mundo globalizado actual pueda ser gobernado por un Estado red es una cuestión abierta. En este plano de discusión se sitúa la propuesta del Estado cosmopolita. «La instituciónalización del estado red en una forma cosmopolita de gobierno podría ser entonces una forma de afirmación colectiva de la soberanía al precio de reducir la autonomía» (2003: Vol. II, 397).

Para que se establezca definitivamente este sistema cosmopolita de gobernanza es indispensable, como reconocen tanto Habermas como Beck, el auge de una cultura cosmopolita en las sociedades del mundo.

En la realidad, tanto la Unión Europea como Estados Unidos se mueven en una dirección opuesta a esta idea. Por tanto, lo que se observa en la era actual es la creciente división entre la globalización de las cuestiones, la autoidentificación de los ciudadanos y la afirmación de los intereses nacionales en el terreno del Estado red informal.

«En último término, el unilateralismo rompe la red en distintas redes e introduce una lógica de confrontación entre ellas. Por tanto, en términos analíticos, la realidad del estado en la sociedad red exige entender tanto la lógica de la red como la dominación, la práctica de la gobernanza global compartida y las nuevas formas de guerra» (2003: Vol. II, 398).

Esta construcción teórica, tal como sucedía con el Estado cosmopolita, no implica que se afirme la desaparición del Estado nacional, en tanto que 
práctica histórica. Para Manuel Castells, la competitividad nacional continúa siendo una función de las políticas nacionales y las políticas económicas nacionales y locales son esenciales para el atractivo de las multinacionales extranjeras. Los Estados nacionales también pueden utilizar sus políticas reguladoras para influir en los movimientos de capital, trabajo, información y bienes. La supervivencia de los Estados nacionales se debe asimismo «(...) al comunalismo defensivo de las naciones y los pueblos de su territorio, aferrándose a su último refugio para no ser arrastrados por el torbellino de los flujos globales» (2003: Vol. II, 399). Esto no obsta para afirmar que los Estados nacionales se han transformado de sujetos soberanos, en actores estratégicos, en un sistema global de interacción, en una situación de soberanía compartida sistémicamente.

\subsection{Propuestas para desarrollos institucionales concretos}

La Teoría Cosmopolita «desde arriba», grosso modo, defiende que, por un lado, el derecho nacional se oriente hacia una soberanía compartida e inclusiva, abandonando, para ello, los nacionalismos excluyentes y los fundamentalismos étnico-culturales. Los Estados nacionales deben cooperar para la realización de esta nueva forma de organización política y consagrar los acuerdos adoptados en el ordenamiento jurídico interno, para garantizar su aplicación. Por otro lado, en relación con el derecho internacional y las organizaciones internacionales existentes, esta construcción teórica aboga por un cambio hacia la instauración de la democracia a nivel mundial y una mayor responsabilidad de los Estados nacionales en el plano internacional, sobre todo, en el ámbito de garantía de los derechos humanos a nivel mundial.

Debido a la dificultad de institucionalización de la propuesta cosmopolita, algunos autores, como se analizará a continuación, proponen el desarrollo de cambios institucionales concretos y limitados. Podrían definirse como los componentes necesarios para dar una solución institucional a la democracia en el orden global, sin llegar a la instauración del orden democrático cosmopolita.

En primer lugar, expondremos la propuesta de David $\mathrm{Held}^{55}$, a favor del desarrollo de una asamblea de Estados y agencias democráticas, directamente elegidas y con poderes reales. Se trataría de «una coalición de agrupaciones políticas que, con el fin de hacer avanzar la agenda de la socialdemocracia, incorporaría a países europeos con fuertes tradiciones progresistas y socialdemócratas; a unos grupos progresistas de Estados Unidos, partidarios del multilateralismo y de la aplicación del imperio de la ley a la política

${ }^{55}$ El desarrollo de esta Asamblea cosmopolita es un tema tratado por David Held a lo largo de todas sus obras analizadas para la elaboración del presente artículo: Held, 1997: 324 a 326 y 2005: 206 a 210; Held y McGrew, 2003: 154. 
internacional; a países en vías de desarrollo que luchan por conseguir normas comerciales más libres y justas para el sistema económicos mundial; a organizaciones no gubernamentales que, desde Amnistía Internacional a Oxfam, promueven un orden mundial más justo, democrático y equitativo; a movimientos sociales transnacionales que ponen en cuestión la naturaleza y la forma de globalización actual, y a las fuerzas económicas que desean una economía global más fuerte y organizada» (2005: 206).

En segundo lugar, para la gestión de problemas de alcance global, delimitados por áreas concretas de conocimiento, Ralf Dahrendorf, en un intento de construir una nueva democracia, propone la creación de «senados éticos» (2002: 127). El citado autor parte de la base de que hay determinados temas que, por los conocimientos científicos que se exigen para poder tomar una opinión fundada sobre ellos, deberían apartarse del debate parlamentario y del principio de la mayoría y debatirse en el seno de cámaras no elegidas popularmente. En torno a estos temas, las decisiones deberían adoptarse por medio de un procedimiento diferente al que está sujeto el debate parlamentario, alejado de juicios mediáticos y de campañas políticas propagandísticas. Con el establecimiento de los senados éticos, no se solucionarán todos los problemas del Estado nacional. Además, debido a su alcance nacional, las decisiones adoptadas en un Estado podrían contrariar la regulación nacional de otro. En un intento de solucionar y superar la nacionalidad de los senados éticos, sería necesario adoptar formas de regulación internacional, en relación con estas materias. Estos debates científicos podrían desarrollarse también en el seno de las organizaciones internacionales pertinentes, en relación con el tema que se deba tratar.

La creación de unos senados éticos es apropiada para los problemas que se están suscitando, no sólo en los Estados nacionales, sino también en la comunidad internacional, debido al progreso científico. Con el desarrollo de este tipo de instituciones se podría, entre otras cosas, lo siguiente: primero, controlar el debate de la comunidad científica, incluyendo a personalidades entendidas, pero de procedencia ideológica; segundo, alejar estos debates de las campañas propagandísticas de los partidos políticos; tercero, superar las fronteras nacionales y la adopción de normas de carácter internacional. Esta propuesta es similar a la de Jean-Marie Guéhemo, quien propone la constitución de administraciones especializadas, por parte de los Estados nacionales, para que elaboren la regulación en los nuevos ámbitos que surgen por el desarrollo tecnológico (2000: 92).

En tercer lugar, centrándonos en el ámbito de la globalización económica, David Held propone el desarrollo de una nueva organización económica que controle y gestione los problemas de distorsión de la competencia: crear una institución financiera internacional, que supla a las ya existentes -Fondo Monetario Internacional, Banco Mundial y Organización Mundial del Comercio- que controle el cumplimiento de los acuerdos adoptados y que cree mecanismos redistributivos de inversión a largo plazo, para ayudar 
a los países en vías de desarrollos y/o a los países subdesarrollados, a avanzar hacia el lado de los ganadores de la globalización. Los Estados nacionales deben garantizar a nivel nacional un control sobre la economía, por medio de mecanismos de rendición de cuentas y control fiscal. Estos datos después deberían ser remitidos a esa novedosa organización supranacional, para conseguir un control global de la economía (1997: 308 y 309 y, sobre todo, 2005: 89 a 101). Para superar el problema de descontrol del mercado global, los Estados nacionales deben, además, adoptar compromisos en este campo y el desarrollo de una regulación jurídica transnacional, en aspectos de producción, comercio y consumo, que impida al mercado financiero y a las empresas transnacionales el desarrollo de su actividad en espacios desregulados.

En cuarto lugar, y siguiendo el hilo de la globalización económica, sería beneficioso para incrementar el control de los Estados nacionales frente a ésta, la creación de una agencia tributaria internacional o de la elaboración de normas internacionales tributarias que gravasen las transacciones mundiales (Condera Campos y Ruesga Benito [coordinadores], 2007).

Con estas propuestas de desarrollo institucional, lo que se pretende es contrarrestar los aspectos negativos de la globalización, así como la pérdida de poder por parte de los Estados nacionales, en aras no sólo de gestionar dichos aspectos, sino de regular y controlar la propia globalización en sí mis$\mathrm{ma}^{56}$.

\section{Propuestas de la corriente cosmopolita «desde abajo»}

\subsection{La globalización «desde abajo» y la democracia normativa}

Richard Falk considera que los efectos negativos de las fuerzas globales del mercado deben encontrar movimientos locales y transnacionales opositores, promovidos por parte de la sociedad civil ${ }^{57}$. Esta emergente sociedad civil global se presenta como un contrapeso de la economía desregulada y pretende (re)instrumentalizar a los distintos Estados nacionales, para que puedan acomodarse a la nueva situación, minimizando, en la medida de lo posible, las consecuencias negativas de la globalización neoliberal imperante. Entre estas consecuencias negativas, ya apuntadas en el presente artículo,

\footnotetext{
${ }^{56}$ No se trata de una propuesta de acción global presentada en conjunto por los autores defensores del cosmopolitismo, sino que cada autor afín a esta construcción teórica aporta una posible solución. Al presentarlas formando un cuerpo organizado se intenta dotar de mayor consistencia a la propuesta de la Teoría Cosmopolita.

${ }^{57}$ Sobre el debate doctrinal actual en torno a la idea de sociedad civil, nos remitimos a lo expuesto en el apartado «1.2.2. Pueblo: Sociedad civil cosmopolita» ya que en este apartado es donde se han recogido las aportaciones no sólo de la corriente cosmopolita «desde arriba», sino también las contribuciones de la corriente que nos ocupa en este momento.
} 
destacan, para el autor aquí analizado, las desigualdades sociales globales y la imposibilidad de una participación-control democrático, en el plano global.

Esta resistencia civil global está en fase de formación y el autor la presenta como una solución democrática aglutinadora de la sociedad, que promoverá acciones a nivel local, regional y/o transnacional, frente a los problemas de la globalización actual. Dichos problemas surgen, sobre todo, por la incapacidad de controlar el mercado global, de satisfacer las necesidades de la sociedad, su bienestar, y de prever y/o solucionar los problemas medioambientales (2002: 193 a 199).

Esta sociedad civil global emergente presenta una carencia muy importante: una ideología alternativa unificada, para hacer frente a la globalización actual y establecer una propuesta alternativa, que aborde los retos normativos más básicos que aúnen Estado nacional, mercado, problemas sociales y medioambientales. Es necesario reconocer que esta sociedad civil global ha demostrado su eficacia en asuntos concretos, esto es, frente a los efectos más negativos de la globalización y/o en campañas locales, pero necesita una construcción ideológica y teórica global que la presente en el plano internacional, nacional y/o transnacional, como una alternativa viable, capaz de gestionar los problemas globales ${ }^{58}$.

Para superar esta situación, Richard Falk desarrolla su propuesta de democracia normativa. La democracia, entendida ésta en términos generales, es una condición esencial para que la sociedad civil global pueda desarrollar su acción política y la democracia normativa, en concreto, pretende actuar como fuerza unificadora de la sociedad civil global para lograr una renovación de la acción política progresista. Se trata de una nueva forma de entender la democracia, en la que ésta es concebida como «algo» (2002: 215) que va más allá de unas elecciones periódicas constitucionales y libres. La democracia normativa debe también incluir un conjunto de garantías adicionales. Estas garantías deben orientarse a asegurar que el ejercicio de poder se conducirá hacia el bienestar humano y el sostenimiento ecológico, y de que los ciudadanos tendrán acceso a los escenarios de toma de decisiones.

Desde los movimientos sociales del Sur del globo, también se ha propuesto una democracia deliberativa o participativa. Se trata, en definitiva, de

${ }^{58}$ Este problema también es reconocido por Boaventura de Sousa Santos, quien afirma que estas uniones cosmopolitas constituidas sobre una base social no clasista pueden sufrir inestabilidad. Esto exige que quienes participen en las uniones mantengan una autorreflexividad permanente y se alejen de las características de las instituciones hegemónicas para el desarrollo de sus iniciativas. La inestabilidad mencionada puede derivarse también de otra circunstancia que no es otra que las diferencias en la concepción de la resistencia emancipatoria por parte de las iniciativas cosmopolitas surgidas en las distintas regiones del sistema mundial (2005: 279). 
desarrollar una nueva redistribución social sobre un nuevo contrato social, que modifique la ecuación entre participación y beneficio social. Es necesario, según estos movimientos, revivir la aspiración y la demanda por la justicia social, por la vía de la participación política activa en actos repetidos, transparentes y mínimamente mediados (Santos, en Santos y Garavito, 2007: 280). Esta propuesta se acerca a los fines perseguidos por Richard Falk en su desarrollo teórico de la democracia normativa.

El cambio de la globalización actual a «otra» globalización, no debe estar únicamente constituida por un movimiento social global, sino que debe dotarse asimismo de agentes políticos que, por medio de la democracia normativa, logren alcanzar una teoría y una práctica coherentes con los objetivos que se persiguen con su instauración. Así, este nuevo movimiento civil y político global será capaz de influir en los entes políticos de gobierno -locales, nacionales, regionales y/o transnacionales- para superar los efectos negativos del proceso globalizador neoliberal hegemónico.

Esta propuesta sólo podrá desarrollarse en un futuro si se dan, al menos, dos condiciones. Por un lado, los Estados nacionales tienen que apartarse de las fuerzas de los mercados globales y optar por una democracia global, que vele por las desigualdades sociales globales actuales. Por otro lado, la sociedad civil global debe afianzar su fuerza de actuación ante los Estados nacionales, las fuerzas del mercado global y la comunidad internacional, y llegar a plantear líneas normativas que, con un alto respaldo social, sean inaplazables de los puntos de la agenda política global.

\subsection{Globalización contrahegemónica y legalidad cosmopolita subalterna}

La propuesta teórica de Boaventura de Sousa Santos surge como consecuencia de la existencia de tres contradicciones. En primer lugar, la contradicción entre globalización y localización. Se están desarrollando simultáneamente procesos de interacción globales desterritorializados y procesos regionales, nacionales y locales basados en la proximidad y la interactividad (2005: 264).

En segundo lugar, la contradicción que se presenta entre Estado nacional y Estado transnacional. Esta contradicción presenta, por un lado, la debilidad organizativa y regulatoria de los Estados nacionales y, por otro, su centralidad en la creación de la globalización. «Cada una de estas posiciones recoge una parte de los procesos en curso. Sin embargo, ninguna de ellas capta cabalmente las transformaciones en su conjunto, porque éstas son, de hecho, contradictorias e incluyen tanto procesos de estatalización -a tal punto que se puede afirmar que los Estados nunca fueron tan importantes como hoycomo procesos de desestatalización en los que interacciones, redes y flujos transnacionales de la más innegable trascendencia se presentan, sin alguna 
interferencia significativa del Estado, contrariamente a lo que sucedía en el periodo anterior» (2005: 265).

Por último, en tercer lugar, la contradicción político-ideológica entre los que ven la globalización como la mejor oportunidad para el capitalismo y los que la ven, por el contrario, como una oportunidad para ampliar la solidaridad y las luchas anticapitalistas al ámbito transnacional (2005: 265).

La finalidad de su propuesta, es decir, del desarrollo de la legalidad cosmopolita subalterna, es la búsqueda de enfoques socio-jurídicos capaces de aclarar las causas y el modo en que cambian las instituciones jurídicas hegemónicas. Con esto, se pretende documentar empíricamente las experiencias de resistencia, afirmar su potencial para subvertir las instituciones e ideologías hegemónicas, reconectar el derecho y la política e imaginar instituciones jurídicas construidas «desde abajo». Todo lo anterior implica, a su vez, dirigir este análisis crítico hacia las formas plurales de resistencia y hacia las alternativas jurídicas que crean periódicamente las bases populares en todo el mundo (Santos y Rodríguez Garavito en Santos y Rodríguez Garavito [eds.], 2007: 17 y 19).

\subsubsection{NuEVO DESARROLLO CONCEPTUAL: SOCIOLOGÍA DE LAS AUSENCIAS Y SOCIOLOGÍA DE LAS EMERGENCIAS}

En la actualidad, el mundo sufre desigualdad, falta de libertad, ausencia de paz y crisis ecológicas. Ante este panorama es necesario desarrollar, según Boaventura de Sousa Santos, una teoría crítica, para superar los diversos rostros actuales de la dominación y la opresión. Para esto, el citado autor defiende el «posmodernismo inquietante o de oposición» (2005: 105). En esta postura sociológica, se asume que existe una disyunción entre los problemas globales que surgen y las posibles soluciones, ya que estas últimas no se llevan a cabo en el plano global. En este contexto, la posmodernidad debe ser convertida en punto de partida, para afrontar desafíos derivados del intento de construir una teoría crítica posmoder$\mathrm{na}^{59}$. Esta propuesta no se centra en el análisis de lo que se expresa como existente (en los medios, en el discurso universitario, en el diálogo social), sino que su centro está en las alternativas silenciadas, en aquello que la modernidad ha renunciado a ver como un problema, porque carecía de solución para ello ${ }^{60}$. La teoría crítica posmoderna, por tanto, debe ser crítica con

${ }^{59} \mathrm{La}$ otra posible postura sociológica propuesta por Boaventura de Sousa Santos, como contraria a la expuesta en el texto del artículo, es el «posmodernismo celebratorio» (Santos, 2005: 104). Esta postura sociológica entiende que la inexistencia de soluciones modernas indica que no hay problemas modernos y, así, lo que existe debe ser aceptado y elogiado.

${ }^{60}$ Esta afirmación de Monedero (en Santos, 2005: 40) es compartida también por Fariñas $(2005,55)$. Esta última autora mantiene también la opinión de que la economía capitalista se fundamenta en que ante ella no existe alternativa posible. 
el conocimiento mismo para conseguir, en última instancia, «una forma alternativa de pensar alternativas» (2005: 106). El posmodernismo de oposición, como discurso alternativo en la sociología actual, es una utopía intelectual, cuyo objetivo último es hacer posible una utopía política que deberá repensar radicalmente el Estado (Monedero en Santos, 2005: 42).

Para conseguir el desarrollo de una postura contrahegemónica y una narrativa diferente del mundo en el que vivimos, es necesario ampliar el presente y contraer el futuro. Así, se aumentará el tiempo y el espacio de reflexión teórica ${ }^{61}$. En primer lugar, para dilatar el presente es necesario el desarrollo de una sociología de las ausencias. Con esto, se trata de identificar las experiencias ausentes en el mundo, para que su ausencia se torne en presencia. El objetivo de la sociología de las ausencias es revelar la variedad y multiplicidad de las prácticas sociales y hacerlas creíbles, por contraposición a la credibilidad exclusiva de las prácticas sociales hegemónicas.

En segundo lugar, la contracción del futuro se obtiene a través de la sociología de las emergencias. Ésta consiste en la investigación de las alternativas que caben dentro del horizonte de las posibilidades concretas, para, por un lado, conocer mejor las condiciones de posibilidad de la esperanza y, por otro, poder definir principios de acción que promuevan la realización de dichas condiciones (2005: 169).

Tanto la sociología de las ausencias como la sociología de las emergencias aumentan enormemente el número y la diversidad de las experiencias disponibles y posibles. Para crear inteligibilidad, coherencia y articulación en un mundo enriquecido por tal multiplicidad y diversidad de tales experiencias, es necesario desarrollar un trabajo de traducción sobre ellas ${ }^{62}$. Este trabajo de traducción, basado en la sociología de las ausencias y en la sociología de las emergencias, es un trabajo de imaginación epistemológica y de imaginación democrática, que tiene como objetivo último constituir nuevas y plurales concepciones de emancipación social sobre las ruinas de la emancipación social automática del proyecto moderno (2005: 186).

${ }^{61} \mathrm{El}$ análisis que se desarrollará a continuación seguirá las aportaciones de Boaventura de Sousa Santos realizadas en Santos, 2005: «Capítulo 4. Hacia una sociología de las ausencias y una sociología de las emergencias», 151 a 192. Parece que vuelve a aflorar la idea, ya comentada en el presente artículo, de que «otra» globalización debiera de ser posible y desarrollada desde la Teoría Cosmopolita tanto «desde arriba» como «desde abajo», véase el inicio del apartado III del presente artículo.

${ }^{62}$ La complejidad del trabajo de traducción se debe sobre todo a dos factores: en primer lugar, a la complejidad de movimientos y organizaciones implicados; en segundo lugar, a los saberes y las culturas tan diversas en las que se encuentran anclados dichos movimientos y organizaciones implicadas (Santos, 2005: 180). «El trabajo de traducción es el procedimiento que nos queda para dar sentido al mundo después de haber perdido el sentido y la dirección automáticos que la modernidad occidental pretendió conferirles al planificar la historia, la sociedad y la naturaleza» (Santos, 2005: 185). 


\subsubsection{VÍAS ALTERNATIVAS AL ESTADO NACIONAL PARA SUPERAR LAS DESIGUAL- DADES GLOBALES}

Alguna de las posibles vías para desarrollar nuevas formas y metamorfosis de los sistemas de desigualdad y exclusión, y superar la gestión ineficaz en estos ámbitos protagonizada por el Estado nacional son el desarrollo de una nueva articulación postmoderna y multicultural entre las políticas de igualdad y las de identidad, la reinvención del Estado nacional y la globalización desde abajo.

\section{A) Políticas de igualdad y políticas de identidad}

El desarrollo de una nueva articulación posmoderna y multicultural entre las políticas de igualdad y las de identidad se refiere a lo siguiente. Los seres humanos tenemos derecho a ser iguales cada vez que la diferencia nos interioriza, pero también tenemos derecho a ser diferentes cuando la igualdad nos descaracteriza. Asumiendo esta máxima, es necesaria la creación de un consenso mínimo alrededor de este imperativo, para que la lucha utópica contra la creciente virulencia de los sistemas de desigualdad y exclusión sea más realista (2005: 222 a 225).

\section{B) Reinvención del Estado nacional}

En relación con la reinvención del Estado nacional, se persigue el cambio del Estado nacional como institución, en el sentido marcado por la globalización contrahegemónica ${ }^{63}$. Con el establecimiento del capitalismo global, se ha podido comprobar que el problema del Estado no se resuelve con la creación de un Estado débil, sino que éste debe modificar su naturaleza (2005: 317). La posición de Boaventura de Sousa Santos frente al Estado nacional es que éste es una entidad en pugna, por un lado, por las empresas multinacionales y, por otro, por los movimientos sociales para salvaguardar, estos últimos, el Estado social.

Desde el punto de vista institucional, esta fase de reforma del Estado nacional se sitúa sobre dos pilares: primero, la reforma del sistema jurídico, sobre todo del judicial; segundo, el desarrollo del llamado tercer sector (2005: 318).

${ }^{63}$ Para una información más amplia sobre esta segunda propuesta, véanse Monedero en Santos, 2005: 80 a 87; Santos, 2005: 225 a 231 y «Capítulo 7. La reinvención solidaria y participativa del Estado», 311 a 338; «11. Reinventar el Estado: el camino hacia una globalización contrahegemónica» (Monedero en Santos, 2005: 80 a 87). 
En relación con la reforma del sistema jurídico ${ }^{64}$, el citado autor entiende que, en la medida en que el papel del Estado nacional ha sido reformado para adecuarse al nuevo consenso global neoliberal, el sistema judicial deberá sufrir también una transformación (en Santos y García Villegas 2001: 160). La atención crítica que reciben ahora los tribunales de justicia «es producto del nuevo papel que se asigna a la justicia como instrumento clave de la buena administración y del desarrollo basado en el derecho» (2001: 161). Según el autor, estamos entrando en una época de expansión del poder judicial a escala global ${ }^{65}$.

Para el desarrollo de este proceso, se establece como hipótesis de partida la existencia de una correlación entre la reforma judicial y legal, por un lado, y el Estado, como sistema político y aparato administrativo, por otro. Por tanto, el asunto de la reforma judicial es, ante todo, un asunto político (2001: 184). La crisis de la democracia y del Estado de Bienestar ha sido asociada con los poderes legislativo y ejecutivo. Este hecho ha inducido a un desplazamiento del núcleo de legitimidad del Estado desde éstos hacia el poder judicial. Este desplazamiento puede traer como consecuencia, en primer lugar, que, en lo sucesivo, la legitimidad democrática resida en el único poder del Estado que no es elegido (2001: 186). Este fenómeno puede tener como segunda consecuencia el desarrollo de una nueva forma de Estado: el Estado post-bienestar (2001: 188). A esta doble causalidad hay que añadir que, sobre todo en los países semiperiféricos, la intervención judicial a favor de los derechos humanos, la protección de los oprimidos y contra la corrupción, ha suscitado expectativas en la reforma judicial (2001: 189). En definitiva, lo que se persigue con esta reforma es la creación de un Estado nacional posterior al ajuste estructural necesario, derivado de la globalización neoliberal (2001: $190)^{66}$.

${ }^{64}$ En el análisis de la conveniencia de una reforma del sistema judicial como vía para la reinvención del Estado nacional seguiremos la explicación de Boaventura de Sousa Santos en Santos y García Villegas, 2001: «Capítulo III. Derecho y democracia: la reforma global de la justicia», 151 a 207.

${ }^{65}$ Para explicar esta afirmación (Santos en Santos y García Villegas, 2001: 162), el autor aporta diferentes razones, divididas según el área geográfica en la que se encuentren los distintos Estados nacionales. En los países centrales, sobre todo en los Estados del continente europeo, el creciente protagonismo de la justicia se debe, en primer lugar, a la percepción pública de una falta de transparencia, responsabilidad y participación en el gobierno y, en segundo lugar, a la pérdida de eficiencia y protección del Estado de Bienestar (2001: 185). En los países semiperiféricos, esta expansión se debe, sobre todo, al deseo de transición de una economía planificada a una economía de mercado por medio de un marco legal y un sistema jurídico fuertes (2001: 166). Este deseo se debe, en la mayoría de los casos, a las presiones del proceso de globalización hegemónica (2001: 177).

${ }^{66}$ La modificación de la base de legitimación de los Estados nacionales, así como su crisis es un tema que se ha estudiado también en la corriente cosmopolita «desde arriba», así como por autores ajenos a dicha Teoría. Véanse Beck, 2002a: 201; Dahrendorf, 2002: 7 a 15; Faria, 2001: 24 y 25; Giddens, 2000: 88; Olivas, 2004: 83 a 122; Rodríguez Carrión en Oliet Palá, 2003: 278; Vallespín en Oliet Palá, 2003: «Democracia y globalización», 145 a 177. 
¿Qué perspectivas para la democracia se originan de la dependencia global del Estado de derecho y del activismo judicial? (2001: 193). A juicio de Boaventura de Sousa Santos, estamos entrando en una nueva fase, una fase de reconstrucción positiva del Estado nacional adecuada a las necesidades reguladoras del nuevo modelo de desarrollo neoliberal consolidado. El interés por el Estado de derecho y por el sistema judicial es uno de los principales componentes de la reconstrucción del Estado nacional que, a juicio del autor, se adelanta en la actualidad (2001: 194).

Para la reforma global de la justicia y la prevención de la sobrecarga del sistema judicial, se propone la resolución alternativa de conflictos o Alternative Dispute Resolution (ADR) ${ }^{67}$.

Para analizar los efectos de esta reforma, Boaventura de Sousa Santos se apoya en dos concepciones distintas de la democracia ${ }^{68}$. En primer lugar, la democracia I es la concepción predominante de democracia actualmente, es la democracia que está siendo globalizada por la globalización hegemónica. Su mayor peligro es que, por definición, puede ser restringida para ajustarla a las necesidades del capitalismo global ${ }^{69}$.

En segundo lugar, la democracia II es una concepción contrahegemónica de la democracia. Ésta, a diferencia de la anterior, considera que en caso de colisión entre democracia y capitalismo, debe prevalecer la primera. Por consiguiente, los criterios que deben cumplir el Estado de derecho y el sistema judicial para cumplir las exigencias de la democracia II son más estrictos que los que se aplican a la democracia I. La democracia II, por tanto, es la promovida por las luchas sociales, utilizando para ello, entre otros, la intervención de los jueces, y podría convertirse en una forma de globalización contrahegemónica. La democracia II encuentra como principal obstáculo para su desarrollo el hecho de que se trata, por definición, de una globalización contrahegemónica. Por tanto, para llevarse a cabo necesita de un movimiento social fuerte y de una ciudadanía activa

${ }^{67}$ El mayor peligro que entraña esta propuesta para Boaventura de Sousa Santos es que el ADR se convierta en una justicia de segunda clase para ciudadanos de segunda clase (en Santos y García Villegas, 2001: 195).

${ }^{68}$ Para más información sobre la democracia I y II véase Santos en Santos y García Villegas, 2001: 193 a 207).

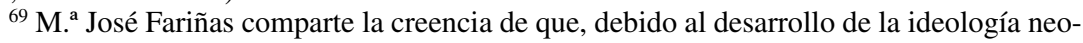
liberal, la democracia, en la actualidad, impone restricciones a la institución del Estado nacional pero no a la institución del mercado (2005: 106). Para ello pone como ejemplo el desigual desarrollo a nivel internacional de la protección de determinados derechos humanos. Para más información véase Fariñas, 2005: «7. Los "derechos del mercado y en el mercado"», 103 a 109. John Gray (2000: 269) también afirma que la democracia y el libre mercado son competidores. Por tanto, el capitalismo democrático oculta una relación profundamente democrática. 
que englobe la reforma-lucha judicial en una reforma-lucha política más amplia $^{70}$.

El segundo pilar institucional en que Boaventura de Sousa Santos basa la reinvención del Estado nacional es el tercer sector ${ }^{71}$. El tercer sector aglutina a todas aquellas organizaciones sociales que, siendo privadas, no tienen fines lucrativos y, siendo no estatales, responden a objetivos sociales, públicos o colectivos. Esta definición permite emplear este concepto para instituciones con raíces ideológicas heterogéneas. Bajo esta definición podemos incluir a cooperativas, mutualidades, fundaciones, ONG, organizaciones de voluntarios, etc. Si el tercer sector, en su conjunto, se rige por unas reglas respetuosas con la autonomía y la integridad de las distintas organizaciones involucradas, su desarrollo puede llegar a constituir el cimiento de las nuevas formas de globalización contrahegemónica.

El desarrollo del tercer sector, en la actualidad, tiene como principal consecuencia que la comunidad, en la modernidad occidental, puede que consiga deshacer la hegemonía que Estado y mercado han venido compartiendo, con distinto peso, en los distintos periodos históricos (2005: 312). El tercer sector, tal y como se plantea en el presente apartado, surge por la propia acción del Estado que promueve su creación mediante políticas de diferenciación positiva respecto del sector privado capitalista.

Es preciso, no obstante, plantear las siguientes advertencias respecto del tercer sector en relación con su desarrollo democrático y su relación con el principio de Estado. En primer lugar, «(...) conviene recordar la advertencia de Rousseau: el tercer sector también puede generar corporativismo» (2005: 320). En segundo lugar, en los países centrales, el tercer sector puede que se consolide como apaciguador de los ataques neoliberales a las conquistas políticas logradas en épocas anteriores. En este caso, puede que el tercer sector se convierta en la solución a un problema insoluble y fracasar, tal y como le ha sucedido al Estado nacional, en primer lugar, y al mercado, en la actualidad (2005: 324). En tercer lugar, es posible que el tercer sector pueda tener con el Estado unas relaciones de clientelismo dependiendo de los pactos políticos que se articulen entre el principio de comunidad y el principio de Estado (2005: 337).

${ }^{70}$ En su obra, Boaventura de Sousa Santos al expresar esta idea sólo se refiere a la lucha judicial y a la lucha política (en Santos y García Villegas, 2001: 207). Sin embargo, al relacionar reforma-lucha se intenta remarca el hecho de que la lucha debe tener como base toda la argumentación ideológica precedente para orientar la lucha. Esto es, la globalización contrahegemónica se apoya en una argumentación sólida que no debe dejarse al margen en el desarrollo de las reformas-luchas sociales.

${ }^{71}$ Para el análisis y la exposición de esta parte del pensamiento de Boaventura de Sousa Santos seguiremos Santos, 2005: 318 a 337. 


\section{C) La globalización «desde abajo»}

En tercer lugar, y como última propuesta para superar la situación actual de desigualdades globales y de exclusión social global, Boaventura de Sousa Santos destaca la importancia del desarrollo de la globalización «desde abajo ${ }^{72}$. Este concepto es sinónimo de la globalización contrahegemónica ya analizada (2005: 281). Los movimientos ajenos a la lógica de la globalización hegemónica imperante, principales actores del impulso de «otra» globalización, se están desarrollando gracias a modos alternativos de producción de la globalización como son el patrimonio común de la humanidad ${ }^{73} \mathrm{y}$ el cosmopolitismo ${ }^{74}$.

Con el primero de ambos conceptos, se trata de destacar que la resistencia a la globalización neoliberal debería producirse por medio del patrimonio común de la humanidad. Este concepto debemos entenderlo como «(...) las luchas transnacionales por la protección y la desmercantilización de recursos, entidades, artefactos y ambientes considerados esenciales para la supervivencia digna de la humanidad y cuya sustentabilidad sólo puede ser garantizada a una escala planetaria» (2005: 280).

El segundo modo de producción de la globalización «desde abajo» es el cosmopolitismo. Éste es definido como «(...) uniones transnacionales de grupos sociales victimizados por los sistemas de desigualdad y exclusión, que establecen redes entre asociaciones locales, nacionales y transnacionales como el medio más eficaz de lucha por sus intereses igualitarios e identitarios contra la lógica de la globalización capitalista» $(2005: 232)^{75}$.

La razón cosmopolita tiene dos objetivos principales: por un lado, identificar nuevas totalidades y adoptar otros sentidos para la transformación social y, por otro, proponer nuevas formas de pensar esas totalidades y de concebir esos sentidos (2005: 174). La razón cosmopolita reclama la constitución de zonas de contacto, es decir, campos sociales donde diferentes puntos de vista normativos, prácticas y conocimientos se encuentran, chocan e interactúan. En estas zonas de contacto se parte del principio de que cada saber o práctica decide qué es puesto en contacto con qué (2005: 181). La razón cosmopolita prefiere imaginar un mundo mejor a partir del presente ${ }^{76}$. De ahí que proponga una dilatación del presente y la contradicción del futu-

\footnotetext{
${ }^{72}$ Para más información sobre este concepto, véase Santos, 2005: 231 a 233; «Capítulo 8. Reinventar la democracia», 339 a 372.

${ }^{73}$ El concepto del patrimonio común de humanidad se define, principalmente, en Santos, 2005: 280 y 281.

${ }^{74}$ Este concepto es analizado por Santos a lo largo de toda su obra (2005); véanse, sobre todo, las páginas 174, 181, 185, 186 y 277 a 281.

${ }^{75}$ Con esta definición, Boaventura de Sousa Santos sitúa el desarrollo cosmopolita «abajo», es decir, en los distintos movimientos sociales y agrupaciones civiles en todos los niveles.

${ }^{76}$ Esta afirmación enlaza con el desarrollo de «otra» globalización; véase, en el presente artículo, el apartado introductorio de «III. Propuestas de la Teoría Cosmopolita».
} 
ro. Aumentando el campo de las experiencias, será posible evaluar mejor las alternativas que son posibles y están disponibles en el momento actual (2005: 186). La resistencia de las uniones cosmopolitas consiste en transformar intercambios desiguales en intercambios de autoridad compartida. Esto se traduce en luchas contra la exclusión, la dependencia, la desintegración y la descalificación (2005: 277). En todas sus variantes, estas luchas tienen como objetivo final la emancipación de las clases dominadas, bien se deba esta dominación a mecanismos de opresión bien se deba a mecanismos de exclusión (2005: 279). Boaventura de Sousa Santos propone, haciendo propios estos objetivos, una reivindicación cosmopolita que permita y promueva la deliberación democrática.

En definitiva, en la actualidad, las luchas democráticas no pueden reducirse al espacio-tiempo nacional, de hecho, «compete a la democracia redistributiva convertir el Estado nacional en elemento de una red internacional que disminuya o neutralice el impacto destructivo y excluyente de esos imperativos y que, en la medida de lo posible, invierta el sentido de éstos en beneficio de una redistribución equitativa de la riqueza globalmente producida» (2005: 371). Así, la lucha nacional por la democracia redistributiva, debe sumarse a la lucha por un nuevo derecho internacional más democrático y participativo.

En el punto concreto de la lucha contra la globalización económica hegemónica, Boaventura de Sousa Santos mantiene que la resistencia más eficaz reside en la promoción de economías de pequeña escala, diversificadas, reterritorializadas, ligadas a fuerzas exteriores aunque independientes de ellas (2005: 281). El impulso de la localización no implica, necesariamente, una negación de las resistencias globales y/o translocales, aunque sí coloca el énfasis en la promoción de las sociabilidades locales (2005: 282). La globalización contrahegemónica debe generar su proliferación en todas partes como respuestas locales a presiones globales y, a su vez, establecer articulaciones translocales entre sí o junto con organizaciones y movimientos transnacionales que compartan parte de sus objetivos (2005: 285).

\subsection{Estado como novísimo movimiento social}

En la actualidad, la reforma del Estado puede inclinarse por dos vías opuestas: por un lado, cabe el desarrollo de un Estado-empresario y, por otro, la constitución de un Estado como novísimo movimiento social. El primero de ellos persigue el liderazgo del mercado frente al Estado. El segundo, por el contrario, persigue el predominio de la comunidad frente al Estado potenciando las relaciones recíprocas entre la comunidad y el Estado (Santos, 2005: 330 y 331).

Las transformaciones tan profundas de las que está siendo objeto el Estado hacen que, bajo la denominación de Estado nacional, esté surgiendo una 
nueva forma de organización política más vasta que el Estado. Esta nueva organización está integrada por un conjunto híbrido de flujos, redes y organizaciones donde se combinan e interactúan elementos estatales y no estatales, nacionales, locales y globales, de los cuales el Estado no es articulador. Esta nueva organización política no tiene centro, la coordinación del Estado funciona como imaginación del centro. La regulación social que surge de esta nueva forma política es mucho más fragmentaria y heterogénea, tanto por sus fuentes como por su lógica, y se confunde fácilmente con la desregulación social (2005: 331). El Estado pierde el control de la regulación social, pero no el control de la metarregulación, es decir, que el Estado selecciona, coordina, jerarquiza y regula las concesiones de poder estatal en agentes no estatales subcontratados políticamente. El tiempo-espacio nacional se ve desbordado por las luchas sectoriales en el espacio público no estatal y el régimen político democrático, al quedar confinado al espacio nacional, no puede garantizar el carácter democrático de las relaciones políticas en el espacio público no estatal (2005: 332 $)^{77}$.

El objetivo final de la construcción cosmopolita es la creación de un nuevo contrato social distinto al desarrollado durante la modernidad que, en última instancia, neutralice la lógica de la exclusión imperante ${ }^{78}$, sobre todo, en los ámbitos en que ésta resulta más flagrante (2005: 360).

Persiguiendo este objetivo, el autor se centra en dos aspectos. En un primer momento, es necesario y urgente el reconocimiento democrático del trabajo para reconstruir la economía como solidaridad democrática ${ }^{79}$. Este propósito debe desarrollarse por medio del alcance de cuatro condiciones (2005: 360 a 371): 1) el trabajo humano debe aprender a compartir su actividad creadora con el trabajo de la naturaleza y debe redistribuirse globalmente la cantidad de trabajo disponible. Para alcanzar este reparto propone tres iniciativas: 1.1) la reducción de la jornada laboral; 1.2) el establecimiento, a nivel global, de unas pautas mínimas en la relación laboral; 1.3) la flexibilización de las leyes migratorias a nivel internacional para facilitar un reparto más

${ }^{77}$ El análisis que hace Boaventura de Sousa Santos, sobre la situación actual del Estado nacional, está muy próxima a la desarrollada por Manuel Castells como justificativa de la existencia de un Estado red, véase apartado 1.4. del presente artículo.

${ }^{78}$ En relación con esta afirmación es necesario hacer dos apreciaciones. Por un lado, la necesidad del desarrollo de un nuevo pacto global, ya ha sido analizada en el presente artículo en la corriente cosmopolita «desde arriba», véase «1.3.Regulación jurídica del Estado cosmopolita: democracia cosmopolita y derecho democrático cosmopolita». Por otro lado, Boaventura de Sousa Santos distingue entre exclusión impuesta por el precontractualismo y exclusión impuesta por el poscontractualismo. El primero, consiste en impedir el acceso a la ciudadanía a grupos sociales que anteriormente fueron considerados candidatos a la misma y que tenían expectativas fundadas en acceder a ella. Por el contrario, el poscontractualismo es el proceso mediante el cual determinados grupos e intereses sociales hasta ahora incluidos en el contrato social quedan excluidos del mismo (2005: 348 y 349).

${ }^{79} \mathrm{La}$ importancia de reconocimiento del trabajo es tratada en Holloway, 2002. 
equitativo del trabajo en todo el mundo. 2) El reconocimiento de los distintos tipos de trabajo debe crear un criterio mínimo de inclusión y se debe promover, para ello, la mejora en la formación profesional. 3) La separación entre el trabajo productivo y la economía real, por un lado, y el capitalismo financiero, por otro. 4) La reinvención del movimiento sindical.

En un segundo momento, el desarrollo de la propuesta de creación de un nuevo contrato social supone la transformación del Estado nacional en un Estado como novísimo movimiento social. Esta construcción se basa en que el declive del poder regulador del Estado nacional tiene como consecuencia su descentralización, ante lo cual el Estado nacional sólo es, en la actualidad, el articulador de los flujos, organizaciones y redes, nacionales y globales, donde está, no sólo el poder estatal, sino también el poder no estatal. Las características principales del Estado en este nuevo marco son las siguientes: la relación política pasa a ser parcial y fragmentada, la lucha política es ahora menos reglada y codificada, existen apertura de un terreno de lucha entre el fascismo social ${ }^{80}$ y la democratización de las funciones de coordinación. El Estado se transforma en componente del espacio público no estatal y, por eso, Boaventura de Sousa Santos denomina a este nuevo ente Estado como novísimo movimiento social. Éste es un Estado articulador que, por un lado, ha perdido el monopolio de la gobernación pero, por otro, conserva el monopolio de la metagobernación, es decir, de la articulación en el interior de la nueva organización política. En este contexto, el Estado como novísimo movimiento aunará dos procesos necesarios y complementarios: la democratización del Estado por la democratización social y, viceversa, la democratización social, por la del Estado (2005: 370).

\footnotetext{
${ }^{80}$ El fascismo social (Santos, 2005: 353 a 358) no es como el fascismo alemán o el italiano, sino que se trata de un fascismo pluralista. Sus principales formas de sociabilidad son éstas: 1) apartheid social: «(...) segregación social de los excluidos dentro de una cartografía urbana dividida en zonas salvajes y zonas civilizadas» (2005: 354); 2) fascismo del Estado paralelo: «(...) aquellas formas de acción estatal que se caracterizan por u distanciamiento del derecho positivo»; 3) fascismo paraestatal: «(...) resultante de la usurpación, por parte de los poderosos actores sociales, de las prerrogativas estatales de coerción y de la regulación social» (2005: 354); 3.1) fascismo territorial: «(...) cuando los actores sociales provistos de gran capital provistos de gran capital patrimonial sustraen al Estado el control del territorio en el que actúan o neutralizan ese control (...). Se trata de territorios coloniales privados (...)» (2005: 355); 4) fascismo populista: crean unos patrones de consumo inalcanzables para la mayoría de la población (Santos, 2005: 355); 5) fascismo de la inseguridad: manipula a los individuos y a los grupos sociales más degradados, bien por precariedad en el trabajo, bien por acontecimientos desestabilizadores (2005: 355); 6) fascismo financiero: ésta es la forma de fascismo social más pluralista, global y secreta (2005: 356 y 357). «Los agentes de este fascismo financiero, en sus varios ámbitos y formas, son unas empresas privadas cuyas acciones vienen legitimadas por las instituciones financieras internacionales y por los Estados hegemónicos. Se configura así un fenómeno híbrido, paraestatal y supraestatal, con un gran potencial destructivo: puede expulsar al estado natural de la exclusión a países enteros» (2005: 358).
} 
Una recomendación para el desarrollo institucional estatal necesario es el denominado Estado experimental. Las grandes mutaciones -impacto cruzado entre espacio-tiempo nacional, global y local; la función de regulación del Estado- y las grandes luchas democráticas de los próximos años se centrarán en los esquemas institucionales alternativos de los cuales surgirá el Estado-articulador aún por inventar (2005: 369). En el proceso de transición paradigmática, las decisiones institucionales irreversibles pueden ser imprudentes. Por tanto, el nuevo Estado democrático, por un lado, debe garantizar su carácter experimental, es decir, que las soluciones institucionales se desarrollen bajo su propia lógica; pero, por otro lado, debe garantizar unas pautas mínimas de seguridad e inclusión que permitan el ejercicio activo de la ciudadanía. Esta situación provocará que la inestabilidad institucional sea un ámbito propicio para la deliberación democrática.

\section{CRÍTICA A LA TEORÍA COSMOPOLITA}

1. En este primer punto crítico con la Teoría Cosmopolita, se analizarán brevemente opiniones contrarias a su base de partida, esto es, a la supuesta crisis del Estado nacional. Para ello, se resaltarán a continuación las supuestas fortalezas de los Estados nacionales. Estas capacidades son suficientes, para algunos autores, como negadoras de la crisis del Estado nacional y como símbolo de su efectividad y vigencia en el desarrollo de las funciones que le son propias. Estos autores, por tanto, niegan la necesidad de superar institucionalmente al Estado nacional. En su caso, alguno de estos autores sólo estima necesario que se reformulen aspectos concretos de dicha institución, tal y como ha sucedido a lo largo de su historia cuando acontecieron otros cambios históricos, culturales, sociales, económicos y/o políticos.

Los aspectos destacados como fortalezas del Estado nacional son los que se analizan a continuación. Primero, capacidad de movilización social. El Estado nacional sigue manteniendo la lealtad de sus ciudadanos (Held, 1997: 127). El Estado nacional es entendido, frente otras instituciones, como la mejor respuesta para maximizar los beneficios sociales y como la única posible frente a enemigos exteriores y las injerencias externas (Rodríguez Carrión en Oliet Palá, 2003: 274 y 275). Así, aunque en algunos casos los ciudadanos estén condicionados por organizaciones y procesos que superan al Estado, es de rigor destacar también que, al mismo tiempo, la intervención del Estado nacional se ha extendido a ámbitos en los que hasta ahora no estaba presente (Attinà, 2001: 158) ${ }^{81}$.

${ }^{81}$ Yendo más allá de la opinión de Fulvio Attinà (2001: 158), Jean-Marie Guéhemo llega a afirmar que «(...) la omnipresencia del Estado, que en ocasiones más parece ser víctima de su propio éxito que encontrarse próximo a su declive» (Guéhemo, 2000: 41). 
En la actualidad, se está produciendo un repunte de los sectores sociales en riesgo por la globalización en torno a la figura del Estado nacional (Tsoulakis, 2004: 79). Los Estados nacionales tienen todavía, por tanto, una fuerte capacidad de movilización social ${ }^{82}$. Esto está relacionado también con la fortaleza territorial del Estado nacional, ya que, generalmente, toda experiencia histórica siempre está ligada a un territorio, incluso en los momentos actuales de globalización donde lo virtual se presenta en todos los ámbitos de la vida del individuo. La experiencia, como desarrollo social concreto, sigue manteniéndose vinculada a la pertenencia a un determinado Estado nacional (Monedero en Santos, 2005: 25).

Segundo, capacidad de movilización empresarial. La mayoría de las empresas transnacionales mantiene fuertes raíces en sus economías y culturas nacionales originarias. Para John Gray no es cierto que el mercado global esté originando corporaciones que asumen las funciones que hasta ahora desempeñaban los Estados soberanos, sino que lo que el mercado global ha hecho es debilitar y vaciar ambas instituciones (2000: 85). «La realidad del mercado mundial de finales del siglo XX es que ni los Estados soberanos ni las empresas multinacionales pueden controlarlo» (2000: 94).

La fortaleza del Estado nacional frente a las empresas transnacionales se observa cuando las empresas transnacionales dedican unos recursos considerables a influir en las políticas de los gobiernos. En la mayor parte del mundo, las instituciones estatales siguen siendo un campo de importancia estratégica fundamental, en el que se libra la competición entre empresas (Gray, 2000: 94). La globalización económica neoliberal no trata de hacer desaparecer al Estado nacional, sino de adaptar su funcionalidad a las exigencias de la lógica del capital mundial y de los mercados globales. Según M. ${ }^{a}$ José Fariñas, las élites empresariales locales y/o globales quieren hacerse, en definitiva, con el control político del Estado nacional (2005: 184). Por tanto, «la pretendida supeditación de la política a la economía no es más que una fábula; ya que, tras la expansión económica global, lo que existe realmente es el intento de consolidar el proyecto de un nuevo "imperio" político y empresarial, basado en el neoconservadurismo ético-religioso, político y militar de la clase económica global dominante» (2005: 183). Este interés de las empresas transnacionales por el poder del Estado

\footnotetext{
${ }^{82}$ Los Estados nacionales siguen concentrando la lealtad de sus ciudadanos. Esta opinión es compartida por Attinà, 2001: 184; Held, 1997: 127; Touraine, 2005: 46. Esta circunstancia tiene como consecuencia que los ciudadanos de un determinado Estado nacional favorecen a otros ciudadanos que ellos consideren como conciudadanos. El concepto de nacionalidad es entendido, en este caso, como una versión ampliada de una familia (Singer, 2003: 180 y 181, siguiendo la interpretación de Michael Walzer). Samuel P. Huntington afirma que el concepto de ciudadanía y movilización social estará cada vez más configurado por factores culturales y civilizatorios, aunque serán los Estados nacionales los que mantengan la posición de mayor importancia en los asuntos mundiales (1997: 39).
} 
nacional se debe a que éste es un elemento de gran peso para el éxito o el fracaso de las empresas que buscan desarrollar su actividad a nivel internacional. Hasta tal punto esta circunstancia es real, que estamos asistiendo en muchos Estados nacionales a un proceso de «re-nacionalización» de empresas privatizadas que, habiendo fracasado en el libre mercado, buscan ahora el proteccionismo estatal (2005: 128). Ganancias y beneficios para los agentes privados $\mathrm{y}$, en cambio, pérdidas sufragadas con los impuestos de todos los ciudadanos ${ }^{83}$.

Tercero, monopolio del ejercicio de la fuerza. Sobre todo desde los autores próximos a la ideología socialista, se destaca que, aunque los Estado nacionales hayan perdido competencias en economía y en aspectos sociales, las de naturaleza represiva, punitiva, policial y carcelaria, en cambio, se fortalecen ${ }^{84}$. Para M. ${ }^{a}$ José Fariñas, se produce una doble cara en la actuación actual de los Estados nacionales democráticos. Por un lado, en el sector formal, el Estado sigue desarrollando sus competencias en relación con los derechos políticos, derechos de libertad, subsidios directos o medidas fiscales regresivas. Por otro lado, en el sector informal o de marginalidad social, el Estado nacional se debilita considerablemente: recorte general en los gastos sociales y asistenciales, regresión cultural, etc., y se refuerza, por el contrario, su función represiva, policial y totalizadora. Como consecuencia de esto, dicha institución nos conduce hacia una dualidad y polarización social de enfrentamiento y desconfianza, entre los sectores sociales integrados y los sectores marginados de efectos hoy imprevisibles (2005: 124).

2. A continuación, se analizará la postura crítica de aquellos autores que aun reconociendo como real la situación de crisis de los Estados nacionales actuales, no consideran que la propuesta cosmopolita sea realizable en la práctica. En esta línea, se encuentra Ralf Dahrendorf. Este autor no está de acuerdo con la alternativa al Estado nacional propuesta por la corriente cosmopolita ya que lo considera un planteamiento utópico. Esta negación de la posibilidad del desarrollo de un futuro Estado mundial se fundamenta en los

\footnotetext{
${ }^{83}$ Esta circunstancia está de plena actualidad. Debido a la crisis financiera que se está sufriendo a nivel mundial, los gobiernos de todo el mundo se han decidido a intervenir visiblemente en sus economías. Ténganse como ejemplos la aprobación en Estados Unidos del plan de rescate económico, la Ley de Estabilización Económica de Emergencia, la primera semana de octubre de 2008; los bancos europeos también están recibiendo ayudas de sus respectivos gobiernos nacionales, por ejemplo, la última semana de septiembre Bélgica, Holanda y Luxemburgo tomaron el control de Fortis; la reunión del G7 el segundo fin de semana de octubre de 2008, cuyo principal objetivo es afrontar la crisis del sistema financiero global, buscar una respuesta consensuada entre los Estados nacionales económicamente más importantes del mundo.

${ }^{84}$ Chomsky en Monereo, Riera y Valenzuela, 2002: 58 y 59; Fariñas, 2005: 122, 123; Santos, 2005: 202; Taibo, 2007: 25.
} 
comportamientos actuales de los Estados nacionales y en su total desacuerdo con la cesión de parte de su soberanía. Este autor aboga por una propuesta a su juicio más factible que la anterior; aboga por un imperio mundial de la ley como una forma de poner freno al poder en vez de intentar eliminarlo (2005, 147 a 150). La propuesta cosmopolita es demasiado abstracta y alejada de la realidad como para acabar con los efectos negativos que, incluso, este autor respalda como propios de la globalización. En este sentido, el citado autor ve más probable que sean los propios Estados nacionales los que doten de mayor poder sancionador a las organizaciones internacionales existentes, pero manteniendo ellos su poder hegemónico y su soberanía nacional intactos.

Algunos de los autores cosmopolitas analizados son conscientes, tanto de este escepticismo provocado por su propuesta, como de las dificultades que realmente entraña llevarla a la práctica, coincidentes con lo apuntado por Ralf Dahrendorf. Tal es el caso de David Held, quien reconoce las dificultades existentes en el ámbito internacional para el desarrollo de la propuesta cosmopolita (1997: 335 a 337 y 2005: 130 a 132). Estas dificultades se deben, sobre todo, a la diversidad de organismos y organizaciones internacionales existentes, con competencias solapadas que, en algunos casos, llegan a adoptar políticas contradictorias. El segundo obstáculo destacable es la falta de responsabilidad política de los Estados nacionales en la gestión de la solución de los problemas globales, así como su negativa a ceder parte de su soberanía a las organizaciones internacionales. Una vez reconocidas estas dificultades, se apela a la madurez de la sociedad civil y a los saltos que se han producido en la historia de forma inesperada, por ejemplo, la caída del muro del Berlín. Un tercer obstáculo, relacionado con el anterior, es la factibilidad política. Esto último es necesario separarlo de la ambición política, es decir, el desarrollo de las diversas políticas nacionales y de la política internacional hacia la alternativa cosmopolita dependerá de la actitud y valentía política de las personas que aglutinen los centros de decisión política. También Ulrich Beck reconoce una dificultad inherente a su propuesta. Así, la Teoría Cosmopolita tiene la dificultad de establecer un conjunto de pesos y contrapesos que controle, desde el exterior, al Estado cosmopolita (2004, 382).

Aunque la postura contraria al cosmopolitismo de Danilo Zolo será analizada, con mayor detenimiento, a continuación, cabe apuntar ahora que, en relación con las premisas necesarias para el desarrollo práctico del cosmopolitismo «desde abajo», dicho autor no considera que la instauración del Estado cosmopolita sea posible porque, en la actualidad, no se dan los factores clave necesarios, tales como a) un proceso recíproco de deslegitimación profunda de los Estados nacionales y de legitimación de la actual organización internacional; b) una desaparición de las desigualdades sociales y económicas a nivel mundial; y c) una homogeneización cultural del planeta. El proceso de globalización no debe hacernos creer que las distintas socie- 
dades nacionales han perdido su fuerza aglutinadora (2000). En esta línea, se podría situar también la aportación de Fernando Vallespín quien, en un artículo titulado «El final de una ilusión», asume la necesidad de un cambio en las instituciones políticas nacionales actuales, pero no considera que la propuesta cosmopolita sea, finalmente, llevada a la práctica en la actualidad. Este autor entiende que la situación de crisis e inestabilidad mundial está teniendo, o tendrá en un futuro próximo, como consecuencia, una vuelta al Estado nacional, es decir, un reforzamiento social, económico, político y jurídico de dicha institución (2008). Esta afirmación puede verse, en la actualidad, debido a la crisis financiera global y el incremento de peso de los Estados nacionales como entes capaces de controlarla, tal y como se ha apuntado en líneas precedentes.

3. En este momento de crítica a la Teoría Cosmopolita puede resultar interesante destacar a Danilo Zolo ya que se define a sí mismo como «realista y anticosmopolitista» (2000: 164) ${ }^{85}$. Este autor no sólo critica la Teoría que nos ocupa en el presente artículo, sino que también desarrolla una propuesta alternativa a ésta ${ }^{86}$. Esta propuesta alternativa es presentada como una estrategia política y económica que superará tanto los aspectos anárquicos del modelo de organización internacional instaurado por el tratado de Westfalia, como del modelo centralista propuesto por el cosmopolitismo jurídi$\mathrm{co}^{87}$.

El citado autor parte de la base de que el orden internacional actual debe ser superado, pero no por medio de una autoridad cosmopolita invasiva, intervencionista y centralista, sino por la vía de organizaciones internacionales descentralizadas y subsidiarias, que coordinen una organización regional sólida, con fuerte arraigo local. Para avanzar en esta dirección, por ejemplo, las organizaciones internacionales existentes -Organización de las Naciones Unidas, Banco Mundial, Fondo Monetario Internacional, entre otras- de-

${ }^{85}$ La Teoría Cosmopolita choca, por definición, con la escuela realista. Esta circunstancia se debe a que estos últimos son defensores de la fortaleza de la institución del Estado nacional. Niegan, por tanto, la Teoría Cosmopolita desde sus presupuestos iniciales, es decir, la supuesta crisis del Estado nacional y su pérdida de poder debido a los procesos de la globalización actuales.

${ }^{86} \mathrm{Su}$ crítica contra la Teoría Cosmopolita de superación del Estado nacional y de la regulación internacional existente la desarrollaremos a la par de la exposición de su propuesta anticosmopolita, denominada por el propio autor como «pacifismo débil». La crítica a la postura cosmopolita, así como el desarrollo de su propuesta, se desarrollan sobre todo en Zolo, 2000: capítulo 4, «La civitas maxima y el derecho cosmopolita», 137 a 176; capítulo 5, «Hacia un "pacifismo débil"»; «Conclusión», 177 a 228, respectivamente. En una obra posterior, el citado autor no sólo se centra en criticar la Teoría Cosmopolita, sino que también se refiere a otros movimientos y sus opiniones ante la globalización actual (2006, 85 a 104).

${ }^{87}$ Este concepto ya ha sido definido en el presente artículo, véase «2. Corrientes ideológicas dentro del cosmopolitismo», nota a pie de página 15 . 
berían reducir su ámbito funcional. En el desarrollo de estas ideas Danilo Zolo, se nutre de conceptos tales como el «orden político mínimo» de Hedley Bull, la «gobernación sin gobierno» de James Rousenau o el «orden anárquico» de Kenneth Waltz (2000: 207, 151 y 150, respectivamente). Conceptos todos ellos referidos a la necesidad de mantener la anarquía existente en el plano internacional y usarla en su beneficio, para crear unas estructuras normativas difusas y policéntricas que impidan la permanencia y el control del orden internacional por parte de potencias hegemónicas.

El primer punto criticado por Danilo Zolo es el enfoque metodológico de la Teoría Cosmopolita. Para el citado autor, el enfoque metodológico de la Teoría Cosmopolita es desacertado, ya que para superar la situación actual existente dentro del derecho constitucional y del derecho internacional emplean la analogía del sistema jurídico de los Estados nacionales. Como consecuencia de esta base conceptual, dicha corriente vincula, desde el inicio, su desarrollo teórico a unos conceptos y a unos métodos comprehensivos de la realidad no válidos para su implantación en el ámbito internacional.

Otra base fundamental del desarrollo de la propuesta cosmopolita es la elaboración de un derecho democrático universal aplicable a nivel mundial. Esta pretensión despierta la crítica de las culturas no occidentales, ya que éstas entienden que dicha construcción supone una nueva forma de imperialismo y que choca con algunas de sus concepciones jurídicas fundamentales. Sirva como botón de muestra que la importancia del individualismo en el mundo occidental es comparable a la importancia de la comunidad en los países islámicos. Juan Carlos Monedero también considera que Ulrick Beck y Boaventura de Sousa Santos -ya que su análisis se centra sólo en estos dos autores- comenten el mismo fallo en el desarrollo de su propuesta. La falta de contacto con el Sur, bibliográfica y vital, de su propuesta se traduce en interpretaciones etnocéntricas, pese a que postulen nominalmente el peligro del etnocentrismo. Ulrich Beck identifica correctamente las «otredades» a menudo ignoradas por Occidente, pero, finalmente, la lectura es la propia de un país central. Es esto lo que imposibilita a este último autor entender qué significa, a fin de cuentas, la globalización desde la perspectiva diferente del globalizador o del globalizado (en Santos, 2005: 42).

Esta cuestión es negada por los autores cosmopolitas en el siguiente sentido. David Held afirma que los orígenes occidentales de los principios cosmopolitas no deben confundirse con su validez (2005: 200). Esta crítica, del imperialismo occidental, surge contra distintos aspectos de la propuesta cosmopolita, por ejemplo, contra la instauración de una ciudadanía cosmopolita. Extremo que también es negado tanto por Anthony Giddens (2000: 29) como por Martha C. Nussbaum (1999: 24). Esta última afirma que la ciudadanía cosmopolita será un paso hacia una mayor conciencia y solidaridad con el resto del mundo.

En definitiva, Danilo Zolo trata de demostrar que llevar a la práctica la Teoría Cosmopolita es imposible, debido a su marcado carácter occidental y 
paternalista. Además, en última instancia, la hipotética creación de un poder cosmopolita a nivel mundial no pondría fin a las consecuencias negativas del proceso de globalización. La propuesta cosmopolita infravalora el rol positivo de los Estados nacionales, que parecen destinados, no sólo a perdurar en el tiempo, sino también a conservar sus funciones tradicionales ${ }^{88}$.

Frente a la autoridad centralizada del poder, Danilo Zolo propone el desarrollo de un orden internacional con estructuras de poder y formas de liderazgo policéntricas. Esta propuesta tendría como ventajas más importantes las siguientes: primero, un mayor reparto del poder, así como una mayor posibilidad de controlarlo y, segundo, daría también respuesta a las reivindicaciones de representación en el plano internacional de los distintos Estados nacionales, además de mantener su diversidad étnico-cultural. En relación con la primera de estas ventajas, el autor es concluyente al afirmar que la falta de pesos y contrapesos en el Estado cosmopolita puede convertirlo en «(...) un Leviatán planetario violentamente represivo y antidemocrático» (2000: 190).

Atendiendo a la representación internacional de los Estados nacionales, la propuesta de Danilo Zolo no aparta a estas instituciones de la actividad política, ya que sobre éstos recaería, en el futuro, el mayor peso para el desarrollo del derecho internacional, pero sobre la base de una distribución policéntrica del poder. De este modo, se daría cabida, en el proceso de organización del Derecho internacional, a nuevos actores internacionales. En este sentido, se podría entender que la propuesta de Danilo Zolo resulta, en parte, coincidente con la Teoría Cosmopolita, ya que ambos otorgan un peso específico a los Estados nacionales en el desarrollo del Derecho internacional, aunque en ambos casos dichas instituciones pierdan su papel hegemónico en dicho ámbito.

4. Tal y como ya se ha apuntado en el punto anterior, la propuesta cosmopolita choca frontalmente con los nacionalismos y los regionalismos excluyentes. Esto es, nacionalismos y regionalismos étnicos, culturales o religiosos que nieguen los derechos fundamentales de las personas sin ningún tipo de distinción se oponen, por definición, al cosmopolitismo. En este último grupo, por ejemplo, se encuentra el fundamentalismo islámico que ve el cosmopolitismo como una nueva forma de dominación occidental postcolonial.

5. Otra parte de la doctrina opuesta al cosmopolitismo se encuentra formada por aquellos autores que lo consideran como corriente política que infravalora el papel humanizador que las políticas de identidad tienen para

${ }^{88}$ Sin ánimo de entrar en contradicción con Danilo Zolo, no tiene presente en este momento de su crítica dos aspectos clave de la construcción cosmopolita. Uno, la necesidad del mantenimiento de los Estados nacionales como instituciones base del Estado cosmopolita. Dos, el carácter subsidiario del Estado cosmopolita frente a la capacidad de acción de los Estados nacionales. 
las personas (Barber en Nussbaum, 1999: 43 a 50). En la misma dirección que esta última crítica al cosmopolitismo puede incluirse el patriotismo. El patriota es entendido como un individuo que se encuentra apegado exclusivamente a un Estado nacional determinado y, por tanto, no comparte el sentimiento inclusivo y universal ${ }^{89}$ que propugna el cosmopolitismo (Bildeny, 2007).

6. Otro punto destacable en la crítica a la Teoría Cosmopolita es aquel que analiza la parte de la doctrina científica que se opone al cosmopolitismo por cuestiones puramente económicas. Según la corriente cosmopolita, como ya se ha apuntado a lo largo del presente artículo, el libre mercado global es un proceso que se ha de superar, ya que siguiendo sus dictados sólo se llegará a luchas y confrontaciones. Por esto, es necesario que los Estados nacionales concentren sus esfuerzos en regular y superar esta fase económica. En este orden de cosas, John Gray (2000) considera que la sustitución de la economía global desregulada por un régimen gestionado de la economía mundial es, en el momento actual, un proyecto casi utópico. Semejante régimen sólo podría establecerse si las grandes potencias económicas del mundo actuaran de común acuerdo en aras de conseguir dicho objetivo. Sin embargo, los conflictos de intereses hacen que la cooperación con cualquier otro propósito más ambicioso que el de la mera gestión de crisis puntuales del sistema global sea casi imposible de lograr (2000: 254 y 255). Este autor considera que debe modificarse la concepción de la economía global, ya que el mercado debe servir al individuo y no a la inversa (2000: 294); para ello, estima como necesario el desarrollo de un régimen de gobernación global en el que los mercados mundiales se gestionen de forma tal, que promuevan la cohesión de las sociedades y la integridad de los Estados nacionales. «Sólo un marco de regulación global -de divisas, de movimientos de capital, de comercio y de conservación medioambiental- puede hacer que la creatividad de la economía mundial se ponga al servicio de las necesidades humanas» (2000: 254). Para lograr esta afirmación, John Gray considera que, por ejemplo, por medio de un impuesto global sobre la especulación de divisas, como el que propuso el economista James Tobin, puede elaborarse un tipo de regulación que haría más estables y productivos los mercados mundiales (2000: 254). Por tanto, este autor, aunque no considera viable la propuesta cosmopolita, sí que apoya el desarrollo de una propuesta institucional puntual, en la que también coinciden los autores cosmopolitas ${ }^{90}$.

${ }^{89}$ En el presente artículo sería quizás más correcto hablar de construcción política y/o jurídica inclusiva y de carácter universal que de una cuestión puramente sentimental, pero la idea, en definitiva, es análoga. Para una introducción a los puntos de conflicto existentes entre el patriotismo y el cosmopolitismo, véase Nussbaum en Nussbaum, 1999: «Patriotismo y cosmopolitismo», 13 a 32 .

${ }^{90}$ Véase el apartado 1.5 relativo a la propuesta cosmopolita «desde arriba» relativa a las propuestas institucionales concretas de desarrollo. 
7. Otro punto objeto de debate en la doctrina científica es el carácter realmente democratizador, o no, de la Teoría Cosmopolita. La (auto)instauración $^{91}$ de una sociedad civil mundial hace relucir unos de los grandes problemas de fondo de esta teoría que podría sintetizarse en la siguiente cuestión: ¿cómo puede llevarse a cabo, en un contexto de democracia global, una participación democrática efectiva?

Esta pregunta ha intentado ser contestada por los autores cosmopolitas en sus distintas propuestas ${ }^{92}$, pero incluso así tiene algunos detractores. En este sentido, tómese como ejemplo la siguiente reflexión de Giovanni Sartori. Este autor, además de criticar la participación democrática en masa como forma realmente efectiva de participación en la actividad política por parte de los ciudadanos, presenta una propuesta alternativa para superar la participación democrática simbólica y no auténtica que se produce en la actualidad. Este avance, en aras de democratizar la participación política, podría lograrse, según el citado autor, por medio de la instauración de unos comités. Estos comités son definidos como pequeños grupos de gestión y discusión política, mediante los cuales se crean ocasiones concretas para una participación efectiva y eficaz (1999: 343).

Las mayores ventajas de los citados comités son, a juicio de Giovanni Sartori, las que siguen. Primero, gracias a la instauración de comités, se saca provecho de la desigualdad de las preferencias individuales, puesto que es precisamente esta desigualdad la que permite un acuerdo transaccional, cuestión por cuestión, que se paga mediante compensaciones diferidas. Segundo, produce la conclusión de acuerdos de suma positiva, es decir, acuerdos en los que todas las partes ganan, bien en el mismo momento temporal o por medio de compensaciones diferidas. Tercero, en el seno de los comités, se producen decisiones discutidas y argumentadas, disminuyendo en gran medida la fuerza de la voluntad preconstituida.

Las ventajas comentadas se incrementan si estos comités son representativos. En este caso, a las ventajas anteriores se les suman las que siguen. Primero, una fuerte reducción de los riesgos externos en la toma de las decisiones, ya que éstas se sustraen al arbitrio de sólo uno y se piden a grupos que han de darles respuesta. Segundo, los costes y los beneficios de las deci-

${ }^{91}$ El uso del término «(auto)instauración» quiere remarcar la diferencia entre las dos corrientes de pensamiento cosmopolita recogidas en el presente artículo. Así, si nos encontramos en el seno del cosmopolitismo «desde arriba» se deberá emplear el término «instauración» porque la dirección en que se creará la sociedad civil cosmopolita será desde el Estado cosmopolita a la sociedad civil. Sin embargo, si nos encontramos en el marco del cosmopolitismo «desde abajo» sería conveniente emplear el concepto «autoinstauración» porque la propia sociedad civil será la encargada de globalizarse y de instaurar en un momento posterior el Estado cosmopolita.

${ }^{92}$ Véase, sobre todo, el caso de Richard Falk y su propuesta de democracia normativa, apartado 2.1 del presente artículo. 
siones tomadas se distribuyen sobre toda la colectividad representada. Tercero, se produce también una fortísima reducción de los costes decisionales, puesto que los mecanismos representativos permiten reducir drásticamente las dimensiones de todo comité (salvando su representatividad) (1999: 345 y 346).

Sin embargo, en el momento de juzgar su propuesta, Giovanni Sartori es también autocrítico con ella y reconoce que la proliferación de un sistema de comités representativos constituye una respuesta adecuada a los problemas de la denominada democracia participativa, en la medida en que su proliferación y/o pluralización no alcance el umbral de la tolerancia funcional, «más allá del cual lo que se gana en el nivel de la "participación descentralizada" se pierde, y se pierde desmesuradamente, en el nivel de la solución, de la eficiencia, e incluso de la eficacia» (1999: 346).

\section{CONCLUSIONES}

1. La aparición del concepto cosmopolitismo no es una novedad en el ámbito de las ciencias sociales, pero sí la importancia que ha adquirido en la actualidad. Esto se debe a su inclusión en el debate científico, en torno a la supuesta crisis de los Estados nacionales, como propuesta alternativa a dichas instituciones. Como principal causa de esta supuesta crisis hemos señalado la globalización económica, que, junto con el desarrollo de los medios de comunicación y los avances técnicos, ha desencadenado el resto de procesos globalizadores.

Esta era de la globalización ha impulsado la necesidad de revisar los conceptos tradicionales de las ciencias sociales, conceptos de tanto calado como Estado nacional, democracia, soberanía, poder, sociedad, cultura, etc. La Teoría Cosmopolita, en todo momento, ha analizado esta nueva situación global desde la necesidad de reducir, en la medida de lo posible, los efectos negativos de la globalización en las distintas sociedades nacionales. Con esta prioridad, el cosmopolitismo intenta avanzar hacia una globalización más humanizada, en la que el peso de los beneficios económicos ceda a favor del bienestar social, el desarrollo económico sostenible, el respeto de la diversidad cultural y la garantía de los derechos humanos. Estos autores aceptan la globalización, en sentido genérico, es decir, la interconexión a nivel global, el desarrollo de la aldea global, pero proponen «otra» globalización diferente a la actual globalización neoliberal hegemónica.

2. En este contexto, la propuesta cosmopolita «desde arriba» se centra en el desarrollo de un Estado cosmopolita democrático. Esta nueva institución no sustituye a los Estados nacionales, sino que se define como una agrupación voluntaria de todos aquellos Estados democráticos que intentará instaurar en todo el mundo un gobierno mundial, capaz de hacer frente a los problemas globales actuales. Para ello, es necesario que se superen los ele- 
mentos tradicionales del Estado nacional, es decir, a) en primer lugar, se deben superar las limitaciones de las fronteras nacionales, ya que éstas han sido superadas por el proceso globalizador y, en la actualidad, obstaculizan el desarrollo del Estado cosmopolita; b) en segundo lugar, se debe promover la participación de la sociedad en el proceso de decisión política; esta sociedad debe abandonar sus ataduras nacionales y desarrollarse sobre una base global; c) en tercer lugar, el poder y la soberanía deben superar su contexto nacional y transformarse en una soberanía incluyente y compartida, en el sendo del Estado cosmopolita. Así, según la Teoría Cosmopolita, si se cumple esta renovación, conceptual e institucional, el Estado cosmopolita podrá resolver de forma eficaz los problemas globales.

El Estado cosmopolita deberá desarrollarse sobre la base de un derecho democrático cosmopolita. Este derecho supondrá una superación de los distintos derechos nacionales y se desarrollará en un plano diferente tanto al nacional como al internacional: se elaborará en el plano transnacional. Por tanto, el derecho internacional seguirá elaborándose por medio de la cooperación internacional entre los Estados nacionales, mientras que el derecho cosmopolita supondrá un proceso de cesión de soberanía por parte de los Estados nacionales que, voluntariamente, se integren en el Estado cosmopolita. El derecho cosmopolita será elaborado directamente por el Estado cosmopolita.

3. La corriente cosmopolita «desde abajo» mantiene los principios y conceptos fundamentales del cosmopolitismo «desde arriba», pero da una mayor importancia a la necesidad de una movilización social que se constituya como fuerza impulsora del cambio institucional necesario. La necesidad de un desarrollo institucional alternativo, superador del Estado nacional, que se mantiene desde toda la corriente cosmopolita, hace que desde esta segunda corriente también se propongan reformas institucionales, tal es el caso de Boaventura de Sousa Santos. Este autor no sólo destaca y analiza el papel de fuerza impulsora de la sociedad civil global como ente revolucionario, sino que también propone un determinado desarrollo institucional: el Estado como novísimo movimiento social.

Esta última circunstancia muestra que la línea de separación entre ambas corrientes cosmopolitas es, más bien, estrecha, y que las grandes diferencias conceptuales, es decir, las diferencias en el empleo o en la defensa de distintos términos entre los autores cosmopolitas se diluyen en el momento de la institucionalización de un ente político y jurídico superior a los Estados nacionales democráticos, superador de las consecuencias negativas de la globalización neoliberal imperante y respetuoso con las diferencias existentes a nivel social y cultural entre los Estados nacionales. En este sentido, es necesario un desarrollo interconectado entre el cosmopolitismo «desde arriba» y «desde abajo», porque, para que un cambio político sea posible, es necesario que la sociedad que va a vivirlo y que va a formar parte de dicha reforma esté preparada y decidida a colaborar, en la dirección política, social y jurí- 
dica adecuada, para que dicho cambio tenga una base de legitimidad democrática suficiente.

4. Las críticas en torno a la propuesta cosmopolita, entendida ésta en sentido amplio, le llegan desde muy diversos sectores de la doctrina científica aunque, en líneas generales, los puntos más conflictivos o más criticados de la teoría aquí analizada serían los dos que siguen. Primero, la negación de la crisis del Estado nacional, esto es, afirmar que dicha institución no se encuentra en el punto en que lo sitúan los cosmopolitas. Negar la mayor, es decir, el fin del Estado nacional, no significa que no exista un debate en torno a la necesidad de reformular o reacomodar dicha institución a la era global.

Segundo, la imposibilidad de institucionalizar un gobierno mundial en el futuro próximo, esto es, el carácter utópico de la propuesta cosmopolita. Una vez admitida la necesidad de reinventar el Estado nacional y avanzar en la investigación de distintas vías de desarrollo que ayuden a su reinstauración de forma eficaz en el plano nacional, internacional y transnacional, el establecimiento y el desarrollo de un gobierno mundial se aleja del terreno de la factibilidad técnica y entra en el campo de la utopía, sobre todo, si se tiene en cuenta el escenario mundial actual: crisis financiera global, incremento del papel de los Estados nacionales ante ella, desigualdades de poder y de desarrollo entre Estados nacionales, así como desigualdades sociales, dificultad del avance en la construcción política en la Unión Europea, falta de democratización en algunos Estados de la comunidad internacional. Este mapa global actual, complejo, diverso, entrelazado, desestructurado, heterogéneo, impide que los elementos necesarios para el desarrollo de un Estado a nivel mundial se consoliden y sean demandados como necesarios por una emergente sociedad civil global.

5. El debate en torno a la situación actual del Estado nacional no sólo se reduce a la Teoría Cosmopolita, sino que gran parte de la doctrina científica -en el campo de la Ciencia Política, de la Sociología, de la Historia, de la Economía y del Derecho- se ha dedicado a estudiar la materia. Por tanto, el artículo aquí presentado es una pequeña reflexión sobre una de las posibles vías de salida del debate, pero éste sigue abierto y es necesario seguir discutiendo sobre él. Para ello, este artículo no se va a cerrar con una conclusión final al uso, sino que se propondrá una serie de obras científicas para poder continuar con la reflexión aquí comenzada ${ }^{93}$.

En relación con el desarrollo institucional europeo, podría ser interesante estudiar el análisis cosmopolita sobre esta cuestión. Para ello, véase $L a$ Europa Cosmopolita. Sociedad y política en la segunda modernidad (Beck y Grande, 2006) así como todo lo relativo a la Gobernanza Europea.

${ }^{93}$ La reseña bibliográfica completa de estas obras se encuentra en un apartado aparte, al final de la bibliografía utilizada para la elaboración del presente artículo. 
En torno al desarrollo institucional a nivel global, podría resultar interesante la comparativa entre dos libros que a priori podrían resultar contradictorio, ambos han sido escritos por Francis Fukuyama. Uno es El fin de la historia y el último hombre (1992) y el segundo es La construcción del estado: hacia un nuevo orden mundial en el siglo XXI (2004).

Referente a la creación de redes en varias de las esferas propias del Estado nacional, por ejemplo, sociedad red o Estado red, podría continuarse el análisis de estos nuevos conceptos con la lectura de La Constitución red: un estudio sobre supraestalidad y constitución (Bustos Gisbert, 2005).

Con estas referencias, se trata de demostrar al lector que este debate es de plena actualidad y que se pueden encontrar multitud de vías abiertas en torno a él, para seguir desarrollando futuras investigaciones sobre la supuesta crisis del Estado nacional, sus supuestas fortalezas y las posibles vías de superación de los efectos negativos de la globalización actual y las posibles nuevas formas de cooperación política para resolver los problemas globales.

\section{Bibliografía general del artículo}

Alfier, C., «Entrevista con Ulrich Beck», Revista de Occidente, n. ${ }^{\circ} 296$, 2006, pp. 109-118.

Appadurai, A., La modernidad desbordada. Dimensiones culturales de la globalización, Ed. Fondo de Cultura Económica de Argentina, Argentina, 2001. ISBN: 950-557-406-1.

AtTINÀ, F., El sistema político global: introducción a las relaciones internacionales, Ed. Paidós, Barcelona, 2001. ISBN: 84-493-1052-0.

Bauman, Z., En busca de lo político, Ed. Fondo de Cultura Económica de Argentina, S. A., Argentina, 2001a. ISBN: 950-557-363-4.

- La posmodernidad y sus descontentos, Ed. Akal, S. A., Madrid, 2001b. ISBN: 84-460-1285-5.

BECK, U., ¿Qué es la globalización? Falacias del globalismo, respuestas a la globalización, Ed. Paidós, Barcelona, 1998. ISBN: 84-493-0528-4.

- Libertad o capitalismo. Conversaciones con Johannes Willms, Ed. Paidós, Barcelona, 2002a. ISBN: 84-493-1204-3.

- La sociedad de riesgo global, Ed. Siglo Veintiuno de España, Madrid, 2002b. ISBN: 84-323-1083-2.

- Poder y contrapoder en la era global: la nueva economía política mundial, Ed. Paidós, Barcelona, 2004. ISBN: 84-493-1617-0.

- La mirada cosmopolita o la guerra es la paz, Ed. Paidós, Barcelona, 2005. ISBN: 84-493-1762-2.

Berger, P. L.; Huntington, S. P., Globalizaciones múltiples: la diversidad cultural en el mundo contemporáneo, Ed. Paidós, Barcelona, 2002. ISBN: 84-4931-322-8. 
Bhagwati, J., En defensa de la globalización. El rostro humano en el mundo global, Ed. Debate, Barcelona, 2005. ISBN: 84-8306-621-1.

BILBENY, N., La identidad cosmopolita. Los límites del patriotismo en la era global, Ed. Kairós S. A., Barcelona, 2007. ISBN: 978-84-7245-656-3.

Boys, G., Una nueva servidumbre. Ensayo sobre la mundialización, Ed. Universidad de Granada y Campus Universitario de Cartuja, Granada, 2004. ISBN: 84-338-3131-3. ISBN: 84-370-5948-8.

Caicedo, A.; Domingo, R.; SAntivánez, M. (coordinadores), Hacia un derecho global. Reflexiones en torno al derecho y la globalización, Ed. Aranzadi, Navarra, 2006. ISBN: 84-8355-101-2.

CASADEI, R., Los mitos de la nueva izquierda. Las profecías incumplidas de la globalización, Ed. Encuentro, Madrid, 2005. ISBN: 84-7490-609-1.

CAstells, M., La era de la información. Vol.1. La sociedad red, Ed. Alianza Editorial, Madrid, 2003 (3. ${ }^{a}$ edición). ISBN: 84-206-7700-0 (Tomo I).

- La era de la información. Vol.2. El poder de la identidad, Ed. Alianza Editorial, Madrid, 2003 (3. a edición). ISBN: 84-206-4740-3 (Tomo II).

Castells, M.; Giddens, A.; Touraine, A., Teorías para una nueva sociedad, Ed. Fundación Marcelino Botín, Madrid, 2001. Depósito Legal: M-3343-2002.

Condera Campos, R,; Ruesga Benito, S. M. (coordinadores), El Estado ante la globalización. Políticas macroeconómicas. Migraciones y empleo, Ed. Marcial Pons, Madrid, 2007. ISBN: 978-84-9768-413-2.

Dahrendorf, R., Después de la democracia. Entrevista de Antonio Polito, Ed. Crítica, Barcelona, 2002. ISBN: 84-8432-343-9.

- En busca de un nuevo orden. Una política de la libertad para el siglo XXI, Ed. Paidós Ibérica, Barcelona, 2005. ISBN: 84-493-1739-8.

Delanty, G., Citizenship in a Global Age: society, culture, politics, Ed. Open, U.P., Buckingham, 2000. ISBN: 0-335-20489-9.

Del Águila, R. (editor), Manual de Ciencia Política, Ed. Trotta, Madrid, 2003. ISBN: 84-8164-189-8.

FALK, R., La globalización depredadora. Una crítica, Ed. Siglo XXI de España, Madrid, 2002. ISBN: 84-323-1076-X.

FARIA, J. E., El derecho en la economía globalizada, Ed. Trotta, S. A., Madrid, 2001. ISBN: 84-8164-464-1.

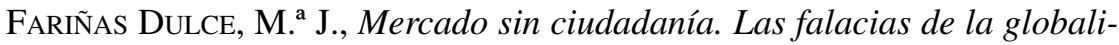
zación neoliberal, Ed. Biblioteca Nueva, Madrid, 2005. ISBN: 84-9742444-1.

Featherstone, M.; Lash, S.; Robertson, R., Global Modernities, Ed. SAGE Publications Ltd, London, 1995. ISBN: 0-8039-7948-7 (pbk).

GIDDENS, A., Un mundo desbocado. Los efectos de la globalización en nuestras vidas, Ed. Santillana, Madrid, 2000. ISBN: 84-306-0385-9.

Gray, J., Falso amanecer. Los engaños del capitalismo global, Ed. Paidós Ibérica, Barcelona, 2000. ISBN: 84-93-07740. 
GuÉHemo, J. M., El porvenir de la libertad. La democracia en la época de la globalización, Ed. Paidós Ibérica, Barcelona, 2000. ISBN: 84-4930969-7.

HELD, D., La democracia y el orden global: del Estado Moderno al Gobierno Cosmopolita, Ed. Paidós, Barcelona, 1997. ISBN: 84-493-0436-9

- Un pacto global. La alternativa socialdemócrata al consenso de Washington, Ed. Santillana Ediciones Generales, Madrid, 2005. ISBN: 84-3060574-6.

Holloway, J., Cambiar el mundo sin tomar el poder. El significado de la revolución hoy, Ed. Revista Herramienta, Argentina, 2002 (2. ${ }^{a}$ edición). ISBN: 987-9306-10-4.

Huntington, S. P., El choque de civilizaciones y la reconfiguración del orden mundial, Ed. Paidós, Barcelona, 2001. ISBN: 84-493-1753-3.

Kant, I., Sobre lo bello y lo sublime. La paz perpetua, Ed. Espasa-Calpe, Madrid, 1979 (6 ${ }^{a}$ edición). ISBN: 84-239-0612-4. Traducción de F. Riera Pastor.

Kelsen, H. Compendio de Teoría General del Estado. Ed. Bosch / Casa Editorial, Barcelona, 1934. Traducción de Luis Recaséns Siches y Justino de Azcárate.

- Introducción a la Teoría Pura del Derecho, Ed. UnAm, Lima, 2001 (3. a edición). Depósito Legal: 1501012001-3387. Traducción de Emilio O. Rabasa.

- La paz por medio del derecho, Ed. Trotta, Madrid, 2003. ISBN: 84-8164572-9. Traducción de Luis Echávarri.

Monereo, M.; Riera, M.; Valenzuela, P. (editores), Hacia el Partido de Oposición. Foro Social Mundial/Porto Alegre 2002, España, 2002. ISBN: 84-95776-39-1.

Nussbaum, M., Los límites del patriotismo: identidad, pertenencia y ciudadanía mundial, Ed. Paidós, Barcelona, 1999. ISBN: 84-493-0675-2.

Oliet Palá, A. (coordinador), Globalización, Estado y democracia, Servicio de Publicaciones de la Universidad de Málaga, Málaga, 2003. ISBN: 849747-000-1.

OLIVAS, E., Sobre algunas consecuencias jurídico-políticas de la globalización, Ed. Reus, Madrid, 2003. ISBN: 84-290-1400-4.

RIFKIN, J., La era del acceso: la revolución de la nueva economía, Ed. Paidós, Barcelona, 2000. ISBN: 84-493-0941-7.

- El sueño europeo. Cómo la visión europea del futuro está eclipsando el sueño americano, Ed. Paidós Ibérica, Barcelona, 2004. ISBN: 84-4931615-4.

SAnTos, B. de S., El milenio huérfano. Ensayos para una nueva cultura política, Ed. Trotta, Madrid, 2005. ISBN: 84-8164-750-0.

Santos, B. de S.; García Villegas, M., El caleidoscopio de las justicias en Colombia. Tomo I, Ed. Siglo del Hombre, Bogotá, 2001. ISBN: 958665-035-9 (Obra completa); ISBN: 958-665-036-7 (Tomo I). 
Santos, B. de S.; Rodríguez Garavito, C. A. (editores), El derecho y la globalización desde abajo. Hacia una legalidad cosmopolita, Ed. Anthropos, Barcelona, 2007. ISBN: 978-84-7658-834-5.

SARTORI, G., Elementos de Teoría Política, Ed. Alianza Editorial, S. A., Madrid, 1999, Segunda edición. ISBN: 84-206-7955-0.

Singer, P., Un solo mundo: la ética de la globalización, Ed. Paidós, Barcelona, 2000. ISBN: 84-493-1490-9.

Tалво, C., Movimientos antiglobalización. ¿Qué son? ¿Qué quieren? ¿Qué hacen?, Ed. Carata, Madrid, 2007. ISBN: 978-84-8319-306-8.

TOURAINE, A., Un nuevo paradigma para comprender el mundo de hoy, Ed. Paidós, Barcelona, 2005. ISBN: 84-493-1819-X.

Tsoukalis, L., ¿Qué Europa queremos?: Los retos políticos y económicos de la nueva Unión Europea, Ed. Paidós, Barcelona, 2004. ISBN: 84493-1546-8.

VAllespín, F., «El final de una ilusión», El País, 24-09-2008.

WIENER, J., Globalization and the Harmonization of Law, Ed. Pinter, London, 1999. ISBN: 1-85567-577-3.

Zolo, D., Cosmópolis. Perspectiva y riesgos de un gobierno mundial, Ed. Paidós Ibérica, Barcelona, 2000. ISBN: 84-493-0706-6.

- Globalización. Un mapa de los problemas, Ed. Mensajero, Bilbao, 2006. ISBN: 84-271-2734-0.

\section{Bibliografía propuesta en la conclusión del artículo}

Beck, U.; Grande, E., La Europa cosmopolita. Sociedad y política en la segunda modernidad, Ed. Paidós, Barcelona, 2006. ISBN: 84-493-1877-7.

Bustos Gisbert, R., La Constitución red: un estudio sobre supraestatalidad y constitución, Ed. Instituto Vasco de Administración Pública, Bilbao, 2005. ISBN: 84-7777-287-8.

Funuyama, F., El fin de la historia y el último hombre, Ed. Planeta, Barcelona, 1992. ISBN: 84-320-595-44.

- La construcción del estado: hacia un nuevo orden mundial en el siglo XXI, Ed. B, Barcelona, 2004. ISBN: 84-666-181-12. 